\title{
Comparative patterns of modified nucleotides in individual tRNA species from a mesophilic and two thermophilic archaea
}

\author{
PHILIPPE WOLFF, ${ }^{1}$ CLAIRE VILLETTE, ${ }^{2}$ JULIE ZUMSTEG ${ }^{2}$ DIMITRI HEINTZ, ${ }^{2}$ LAURA ANTOINE, ${ }^{1}$ \\ BÉATRICE CHANE-WOON-MING, ${ }^{1}$ LOUIS DROOGMANS, ${ }^{3}$ HENRI GROSJEAN, ${ }^{3}$ and ERIC WESTHOF ${ }^{1}$ \\ ${ }^{1}$ Architecture et Réactivité de I'ARN, Institut de Biologie Moléculaire et Cellulaire du CNRS, Université de Strasbourg, \\ F-67084, Strasbourg, France \\ ${ }^{2}$ Institut de Biologie Moléculaire des Plantes du CNRS, Université de Strasbourg, F-67084, Strasbourg, France \\ ${ }^{3}$ Laboratoire de Chimie Biologique, Université Libre de Bruxelles, Institut Labiris, B-1070, Belgium
}

\begin{abstract}
To improve and complete our knowledge of archaeal tRNA modification patterns, we have identified and compared the modification pattern (type and location) in tRNAs of three very different archaeal species, Methanococcus maripaludis (a mesophilic methanogen), Pyrococcus furiosus (a hyperthermophile thermococcale), and Sulfolobus acidocaldarius (an acidophilic thermophilic sulfolobale). Most abundant isoacceptor tRNAs (79 in total) for each of the 20 amino acids were isolated by two-dimensional gel electrophoresis followed by in-gel RNase digestions. The resulting oligonucleotide fragments were separated by nanoLC and their nucleotide content analyzed by mass spectrometry (MS/MS). Analysis of total modified nucleosides obtained from complete digestion of bulk tRNAs was also performed. Distinct base- and/or ribose-methylations, cytidine acetylations, and thiolated pyrimidines were identified, some at new positions in tRNAs. Novel, some tentatively identified, modifications were also found. The least diversified modification landscape is observed in the mesophilic Methanococcus maripaludis and the most complex one in Sulfolobus acidocaldarius. Notable observations are the frequent occurrence of $\mathrm{ac}^{4} \mathrm{C}$ nucleotides in thermophilic archaeal tRNAs, the presence of $\mathrm{m}^{7} \mathrm{G}$ at positions 1 and 10 in Pyrococcus furiosus tRNAs, and the use of wyosine derivatives at position 37 of tRNAs, especially those decoding U1- and C1-starting codons. These results complete those already obtained by others with sets of archaeal tRNAs from Methanocaldococcus jannaschii and Haloferax volcanii.
\end{abstract}

Keywords: mass spectrometry; Archaea; tRNA; modifications; hyperthermophiles

\section{INTRODUCTION}

Transfer RNAs are the most modified RNA molecules in terms of number of modified positions and diversity of chemical modifications. A whole gamut of modification enzymes had to differentially evolve in the three domains of life to mature properly tRNAs (Helm and Alfonso 2014; Boccaletto et al. 2018). In short, tRNA modifications play two central roles. The first one is to guarantee the maintenance of the uniqueness and stability of the tRNA architectural fold (Helm 2006; Motorin and Helm 2010, 2011), a requirement for proper recognition by key factors like aminoacyl-tRNA synthetases (Giégé and Springer 2016), the Elongator complex (Karlsborn et al. 2014), and

Corresponding authors: e.westhof@ibmc-cnrs.unistra.fr, p.wolff@ibmc-cnrs.unistra.fr

Article is online at http://www.rnajournal.org/cgi/doi/10.1261/rna. 077537.120. Freely available online through the RNA Open Access option. ribosomal subunits (Selmer et al. 2006). The modifications occur in the whole body of the tRNA but especially in the elbow created by the intricate contacts formed between the D- and T-loops (Machnicka et al. 2014). The second main role played by tRNA modifications is to guarantee fidelity and efficiency during ribosomal translation at the decoding site, thereby participating in the regulation of the translational activity and the control of proteostasis (Pollo-Oliveira and de Crécy-Lagard 2019). These modifications occur mainly in the extended anticodon loop of tRNAs (Yarus 1982). Their roles are (i) to maintain a conformation of the anticodon loop preorganized for pairing with the mRNA codon in the A site (Vendeix et al. 2012); (ii) to stabilize the weak AU-rich codon/anticodon pairs (Grosjean and Westhof 2016); (iii) to avoid miscoding (e.g., Met/lle or Trp/Stop) (Cantara et al. 2013); (iv) to allow

(C) 2020 Wolff et al. This article, published in RNA, is available under a Creative Commons License (Attribution 4.0 International), as described at http://creativecommons.org/licenses/by/4.0/. 
the decoding of purine-ending codons in split codon boxes by promoting unusual base-pairings that fit within the decoding ribosomal grip (Rozov et al. 2016). Although the nature and number of the modifications vary considerably between the three domains of life, the great majority of the tRNA positions that are modified are highly conserved throughout phylogeny.

Unfortunately, the complete patterns of tRNA modifications are known for only a limited number of species (e.g., E. coli in Bacteria or S. cerevisiae in Eukarya). In Archaea, although studied for a long time, the landscape of tRNA modifications remained disperse, and known only for a few particular tRNA isoacceptors or bulk cellular tRNAs (see for examples: Kuchino et al. 1982; Edmonds et al. 1991; Tomikawa et al. 2013). Only in the cases of Haloferax volcanii (Gupta 1984, 1986; Grosjean et al. 2008a) and very recently in the case of Methanocaldococcus jannaschii $(\mathrm{Yu}$ et al. 2019), the modification landscape of a complete set of cellular tRNAs has been elucidated. These data reveal that a few modifications are unique to certain archaea, while others are present in most, if not all archaeal species studied so far. Among the archetypal ones are a N1-methylated pseudouridine at position 54 instead of a thymine (Pang et al. 1982; Gupta 1984), the presence of archaeosine, or 7-formamidino-7-deazaguanosine, at position 15 (Watanabe et al. 1997), certain wyosine derivatives like imG, imG2 and mimG at position 37 (de Crécy-Lagard et al. 2010) and the presence at position 34 of tRNA-Ile of agmatidine, a modified $\mathrm{C}$ where the carbonyl group is replaced by decarboxy-arginine (Ikeuchi et al. 2010; Mandal et al. 2010).

Here, we examined the landscapes of tRNA modifications in three archaeal species with very different evolutionary history. Two belong to the Kingdom Euryarchaeota: Methanococcus maripaludis, a methane-producing anaerobic mesophilic archaeon belonging to the same Methanococcales clade as $M$. jannaschii (but the latter is thermophilic) and Pyrococcus furiosus, an anaerobic hyperthermophilic archaeon belonging to the Thermococcales clade (Forterre 2015). The third species studied here is Sulfolobus acidocaldarius (an obligate aerobic, acidophilic, sulfur-oxidizing thermophile that belongs to the Sulfolobales clade of the Crenarchaeota Kingdom). The last two archaea therefore belong to families not yet systematically analyzed and S. acidocaldarius is the first crenoarchaeon for which the modification landscape is reported. Further, all euryarchaeal tRNAs analyzed so far are from anaerobic microorganisms (with thermophilic or hyperthermophilic character), while $S$. acidocaldarius is an aerobic moderate thermophile.

As performed earlier in the case of $H$. volcanii (Gupta 1984, 1986), two-dimensional gel electrophoresis was used to separate individual tRNA isoacceptors from purified bulk cellular tRNAs of each of the three archaea, allowing the analysis of 79 cellular tRNAs out of a total of 116 theoretical corresponding tDNA genes (Chan and Lowe 2009, 2016). In-gel digestion by specific nucleases followed. The resulting tRNA digests, for which sequences were deduced from their known genomes, were then separated by chromatography and analyzed by mass spectrometry. The analysis of modified nucleosides of bulk tRNAs was also performed and the results compared with those obtained from the analysis of oligonucleotide sequences. Altogether, our results support the idea that, despite the fact that Archaea share typical modified nucleotides present in both Bacteria and/or Eukarya, they also display unique and specific modifications.

\section{RESULTS}

\section{tRNA genes and their cellular mature products}

In the GtRNAdb (Chan and Lowe 2009, 2016), there are 37 genes coding for tRNAs in M. maripaludis and 46 in both $P$. furiosus and $S$. acidocaldarius, all predicted with excellent scores using tRNAscan-SE 2.0 (Lowe and Eddy 1997). In S. acidocaldarius, 50 tRNA genes are predicted but four have scores below 45.0 and would be considered as pseudogenes (Chan and Lowe 2009, 2016). Based on genomic information, in M. maripaludis, there are only two tRNA genes corresponding to 4-codon boxes and only one gene corresponding to 2-codon boxes, except for Asp, Glu, and Lys where there are two isoacceptors. In $P$. furiosus and $S$. acidocaldarius, there are three genes coding for isoacceptors in 4-codon boxes and only one in 2-codon boxes, except again for Glu, Lys, but also Gln, lle, Arg(AGR), and Leu(UUR) (all codons of 2/3-codon boxes ending with R3 and thus decoded by Y34-containing tRNAs). In the three species, there is one gene coding for tRNA-Met ${ }^{i}$ and another one for tRNA-Met, except in M. maripaludis, where there are two copies of tRNAMet'. As in all other archaeal genomes sequenced so far, there is no gene coding for A34-containing tRNA. Remarkably, in M. maripaludis, the C34-containing tRNAs are absent in both 4- and 2-codon boxes except of course in tRNA-lle(CAU), tRNA-Met and tRNA-Met'(CAU), and tRNA-Trp(CCA). Thus, besides these five particular tRNAs, all the other tRNA anticodon triplets start with either G34 or U34. In contrast, in the two thermophilic archaea, $P$. furiosus and S. acidocaldarius, the C34-containing tRNAs are present, which explains the increase from 37 to 46 naturally occurring tRNA genes. These distributions follow the sparing strategies in Archaea described by Grosjean et al. (2010). The percentage of GC-content increases from M. maripaludis (34\%) to S. acidocaldarius (37.5\%) and to $P$. furiosus (41.1\%). The codon usage is such that U3- and A3-ending codons are highly preferred (Nakamura et al. 2000; Emery and Sharp 2011; Nayak 2013). This is particularly striking in the mesophilic M. maripaludis where U3and A3-ending codons are decoded solely by G34-tRNAs 
and U34-tRNAs, respectively. In M. maripaludis, the percentage of GC-content at the third position is $25.6 \%$, while it is $28.8 \%$ in $P$. furiosus and as high as $39.3 \%$ in S. acidocaldarius. Such differences in decoding strategies have consequences on the modification identity found at position 34 and in the extended anticodon stem-loop of individual isoacceptor tRNA (see below and Grosjean and Westhof 2016). The knowledge of tRNA genes and copy numbers does not allow yet to predict which identified genes correspond to lowly or highly expressed cellular tRNAs (minor/major species). The low abundance of certain cellular tRNAs can be below the detection mapping method, which explains why some tRNA isoacceptors are missing in our analyses of bulk tRNAs. However, for each archaeon, representative tRNAs corresponding to each of the 20 amino acids could be analyzed. They probably correspond to the most abundant naturally occurring species. Lastly, in Archaea, especially the hyperthermophilic ones, tRNA genes often contain introns (Sugahara et al. 2008). Among the three archaeal species studied, the S. acidocaldarius contains the highest number of tRNAs with introns (21 out of 46) (Chan and Lowe 2009, 2016). Such intron-containing tRNAs are often the targets of site-specific 2'-O-ribose methylations or uridine isomerization into pseudouridine via the sRNA-guided FIpA C/D box or the Cbf5 H/ACA enzymatic machinery, respectively (see below).

\section{Purification and sequencing of isolated tRNA species}

Each tRNA isoacceptor was isolated using two-dimensional PAGE. The process leads to a series of tRNA spots. Each spot contains generally one isoacceptor, while some contain two or rarely three isoacceptors (Supplemental Fig. S1). For each spot, all CID spectra were manually inspected and sequenced. The tRNAs were identified by unique sequences in RNase digestion products (see Materials and Methods). From such 2D-gel electrophoresis, we could purify and analyze 27 post-transcriptionally matured tRNAs corresponding to obviously major naturally occurring species from M. maripaludis and 30 tRNAs from $P$. furiosus (over 37 and 46, respectively) but only 22 (over 46) from S. acidocaldarius. In this latter case, of the 21 intron-containing primary transcripts predicted from the genome sequence only six were identified as matured species in the purified bulk matured tRNAs, while 16 over 25 of the predicted intron-less tRNAs were detected. In $P$. furiosus and M. maripaludis, only two tRNAs (specific for Met [CAU] and $\operatorname{Trp}[C C A]$ ) are transcribed as intron-containing species and each of them was obtained and analyzed as the matured species.

A critical point in the present experimental strategy is to assign a modified position to the tRNA it belongs to. Indeed, because archaeal tRNAs are highly GC-rich (especially in stems), there is a high level of similarities between
tRNA sequences especially for the highly conserved $D$ - and TYC-loops. To be sure to assign unambiguously an MS/MS sequencing spectrum, each tRNA isoacceptor was analyzed separately (see Materials and Methods). All CID (Collision Induced Decay) MS/MS spectra were manually examined and sequenced. Although LC MS/MS spectra of digestion products allow the localization of a modified nucleotide within the sequence, some of the modifications unfortunately share the same $(\mathrm{m} / \mathrm{z})$ mass. For example, methylation can be detected but, solely on the basis of the mass spectra, it is not possible to localize the methyl group (either on the ribose or on the base). The same situation occurs between uridine and pseudouridine. However, knowing the presence of a given modified nucleotide at the same position in a homogous tRNA of a closely related archaeon, together with the existence of corresponding modification enzymes (and its ORF in the genome), sometimes allows to assign the most probable chemical modification after verification that a homolog gene exists in the genome of the archaea studied (Supplemental Table S2). The ambiguous cases that are left are discussed in the text or legends. Analyses of total modified nucleosides of bulk tRNAs were also performed allowing to identify the presence of modified nucleotides that escape the above analysis of sufficiently long oligonucleotides (Supplemental Figs. S2, S3). The code for modified nucleosides used throughout this paper, except when specifically mentioned, follows either the one used in MODOMICS (Boccaletto et al. 2018) or the chemically based nomenclature (Motorin and Helm 2011; Helm and Alfonso 2014).

\section{Structural tRNA alignments}

Alignments of the sequenced archaeal tRNAs studied in this work, including the modified nucleotides we have been able to detect at the oligonucleotide digest products, are shown in Figure 1 (see also Table 1; Supplemental Fig. S10). These alignments follow the usual nomenclature of tRNA structure, and they are structural in the sense that equivalent positions in the three-dimensional structure (assumed by homology with known crystal structures) are vertically aligned. They show that the tRNA sequences follow the expected patterns of covariations and conservations as observed in the majority of cellular tRNAs of all three domains of life, demonstrating that they do conform to the known three-dimensional structure of tRNAs. The numbers of Watson-Crick base pairs (often GC-rich and with a small number of GU pairs, especially in the thermophiles) in the stems are as usual: seven in the acceptor stem (AA-stem), four in the dihydrouridine stem (D-stem), five in the anticodon stem (AC-stem) and the thymine stem (TYC-stem). Also, a long variable region is always present in the longarm tRNAs specific for leucine and serine. The tRNA-Leu (anticodons $Y A G, Y=U / C$ ) in $M$. maripaludis and $P$. furiosus 


\begin{tabular}{|c|c|c|c|c|c|c|c|c|c|c|c|c|c|c|c|c|c|}
\hline & & & & & & & & & & & & & & & & & \\
\hline & & 1 & 8 & 10 & 14 & 22 & 26 & 27 & 32 & 39 & 44 & 49 & 54 & 61 & 66 & 74 & 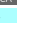 \\
\hline naripaludis & & & & & & & & & & & & & & & & & \\
\hline Ala & UGC & GGGCCCG & UA & gcuc & A[G+]UUGGGA & [Gm]AGC & G & ccosc & CUUGC/[ac4C/AAA & 6G606 & Agcuc & GUGGG & {$[m 1 Y][\mathrm{cm}][\mathrm{m} 11][\mathrm{m} 1 \mathrm{~A}] \mathrm{AU}$} & $\operatorname{ccccoc}$ & CUAGGCU & & \\
\hline Arg & ucu & GGGCCCG & ug & sccu & AgUCUGGAUA & $\operatorname{CGGC}$ & A & $\operatorname{ccGGC}$ & cuucuttraja & $\sec 6 \theta$ & Ggauc & GGGGG & [m1Y]UCG[m1A]AU & cccuc & coGGucc & G cc. & \\
\hline Asn & GUU & GCCUCCU & UA & GCUC & A[G+] UAGGUAG & CAGC & {$[\mathrm{m} 2,2 \mathrm{G}]$} & ACGGA & CUGUU[hn6A]A & UCCGU & AGGUC & GCAGG & UUCGAGC & CCUGC & AGGAGGC & $G \mathrm{cCA}$ & \\
\hline Asp & Guc & GCUCUGG & ug & GUGU & $A[G+]$ CUCGGCCUA & UCAU & A & CAGGA & $\operatorname{cug} \underline{U}[(6 \mathrm{fA}] \mathrm{C}$ & UCCUG & UGAC & UCGGG & {$[m 1 \gamma] \cup[(\mathrm{cm}][\mathrm{m} 11][\mathrm{m} 1 \mathrm{~A}] \mathrm{AU}$} & CCCGG & CCAGAGC & G CCA & \\
\hline Glu & uuc & GCUCCAG & ug & {$[\mathrm{m} 2,2 \mathrm{G}] \cup G \mathrm{U}$} & AGUCCGGCCAA & UCAU & c & cGGCC & cu[mnmsU]UC[m1G]A & GGCCG & GGAC & UCGGG & {$[\mathrm{m} 1 \mathrm{Y}] \mathrm{U}[\mathrm{cm}][\mathrm{m} 1][\mathrm{m} 1 \mathrm{~A}] \mathrm{A} U$} & $\operatorname{coc} G \theta$ & CUGGAGC & A CCA & \\
\hline Gly & occ & GCGGCUU & ug & AUGU & A[G+]ACUGGUA & UCAU & A & CGGCC & CUGCCAC & GGCCG & ACAC & $\operatorname{cctgG\theta }$ & UUCAAAU & $\operatorname{ccc} \theta$ & AGGCCGC & & \\
\hline Gly & ucc & GCGCCAG & ug & GUGU & AGCCUGGUA & UCAC & $u$ & UUGGC & CU[SnmSU]cCAA & GCCAG & UAAC & UCGGG & {$[m 1 \gamma] U[\mathrm{Cm}][\mathrm{m} 11][\mathrm{m} 1 \mathrm{~A}] \mathrm{AU}$} & $\operatorname{cCCGA}$ & cusGcec & A $C$ CA & \\
\hline His & GUG & GCCGUGG & UA & GGGU & AGUGGCUA & uccu & G & AGGGA & CUGUG[m1G]A & ucceu & CGAC & $\operatorname{ccc666}$ & uucgauu & $\operatorname{cccs} \theta$ & ucucGec & c cc. & \\
\hline He & GAU & AGGGCAG & ug & gcuc & $A[G+][[52] \cup G G \cup \cup A$ & GAGU & {$[\mathrm{m} 2,2 \mathrm{G}]$} & cucco & CUGAUU[hn6A]A & CCGAG & | ugGuc & c6066 & UU[Cm]G[m1A]AU & $\operatorname{ccccc} \theta$ & cuscccu & A $C$ CA & \\
\hline Nle & CAU & GGGCCCG & UA & Gcuc & AGGCUGGUU-A & GAGU & {$[\mathrm{m} 2,2 \mathrm{E}]$} & CuCGG & $\mathrm{CU}[\mathrm{C}+] \mathrm{AU}[\mathrm{h} h 6 \mathrm{~A}] \mathrm{A}$ & CCGAG & [ugGuc & AUGGG & $[m 1 \gamma] U[c m][m 1]][m 1 A] A U$ & CCCAU & cGGGccc & A & \\
\hline Ini & CAU & AGCGAGG & UA & GGGU & A[G+]CCAGGCCUA & ucce & G & $\operatorname{ccGGG}$ & CUCAUAA & $\operatorname{coc} \theta 6$ & AgAuC & AGAAG & UUCAAAU & cuucu & ceucocu & A $C C A$ & \\
\hline Leu & GAG & GCGAGGG & uu & GCCA & A[G+][[52C]UGGUUAA & AGGC & {$[\mathrm{m} 2,26]$} & CUAGG & UUGAGGG & CUUAG & | UCUCAUAGGAGUUC & GAGGG & UuCG[m1A]AU & ceccuu & cecucoci & & \\
\hline Leu & UAA & GGAGGGA & uu & GCCA & AGCCUGGUCAA & AGGC & G & UCGGA & CUUAAGA & UCCGA & | UCCGGUAGCGGUUC & GAGGG & UUCAAAU & cecuu & ucccuuce & A & \\
\hline Leu & UAG & GCAGGGG & uu & GucG & A[G+] CCUGGCCAA & AGAU & {$[\mathrm{m} 2,26]$} & CAGGA & {$[[s 20][\times]] A G A A$} & Uccus & | UCCAGUAGUGGUUC & CAGGG & UUCAAAU & cccug & cceccusc & A & \\
\hline $\begin{array}{l}\text { Lys } \\
\text { Met }\end{array}$ & ous & GGGCCCG & UA & {$[\mathrm{m} 2 \mathrm{G}] \mathrm{CUU}$} & A[G+]UCUGGUA & GAGC & {$[m 2,26]$} & CCUGA & cu[cmnm5s2u]UU[t6a]A & UCAGG & cGGuc & GAGGG & UUCG[m1A]AU & cecuu & cGGGccec & $G$ CCA & \\
\hline $\begin{array}{l}\text { Met } \\
\text { Phe }\end{array}$ & CAU & GCCGAGG & UG & GCUU & A[G+]GCUGGUUA & UAGC & {$[\mathrm{m} 2,26]$} & cuccs & cu[Cm/AUUhnGA]A & CCGAG & AGGUC & GGGGG & [m1]UU[Cm][m11]AGU & ccccec & ceucGGe & & \\
\hline $\begin{array}{l}\text { Phe } \\
\text { Pro }\end{array}$ & GAA & $\begin{array}{l}\text { GCAAAGG } \\
\text { GGGCUG }\end{array}$ & UA & Guuc & AGCCUGGGA & GAAC & {$[\mathrm{m} 2,26]$} & CUGGA & [Cm]UGAA (imG-14]A] & UCCAG & ungue & GGGUG & UU[Cm][m11][m1A]]AU & сассC & CCUUGGC & A $\mathrm{CCA}$ & \\
\hline $\begin{array}{l}\text { Pro } \\
\text { Thr }\end{array}$ & UGG & $\begin{array}{l}\text { GGGCCUG } \\
\text { GCUUCG }\end{array}$ & ug & GGGU & A[G+]CCUGGUCA & uccu & $u$ & UGGGA & UUUGG[M1G]A & $\begin{array}{l}\text { UCCUG } \\
\text { GGAG }\end{array}$ & AAAC & CCAAG & UUGG[m1A]AU & CUGGG & CAGGCCC & A $\mathrm{CCA}$ & \\
\hline $\mathrm{Thr}$ & $\begin{array}{l}\text { GGU } \\
\text { UGG }\end{array}$ & $\begin{array}{l}\text { GCUUCAG } \\
\text { GCCUCGG }\end{array}$ & $\begin{array}{l}\text { UG } \\
\text { UG }\end{array}$ & $\begin{array}{l}\text { Gcuc } \\
\text { Gcuc }\end{array}$ & $\begin{array}{l}\text { A[G+CCCUGGUA } \\
\text { AGCUGGA }\end{array}$ & $\begin{array}{l}\text { GAGC } \\
\text { GAGC }\end{array}$ & ${ }_{6}^{[m 2,26]}$ & 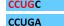 & 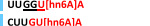 & $\frac{\text { GCAGG }}{\text { UCAGG }}$ & $\begin{array}{l}\text { AGGCC } \\
\text { AGGY }\end{array}$ & GCGGG & UUCAAAC & $\operatorname{cccccc}$ & CUGAAGG & u & \\
\hline Trp & CCA & GGGAGUA & ug & Gugu & $\begin{array}{l}\text { AGCCUGUA } \\
\text { A[G+]U[S2C]UGGUCUA }\end{array}$ & UCAU & c & GGGAA & 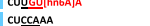 & $\begin{array}{l}\text { UCAGG } \\
\text { UCCCU }\end{array}$ & $\begin{array}{l}\text { UGGAC } \\
\text { GGAC }\end{array}$ & $\begin{array}{l}\text { GGGGG } \\
\text { CUGG }\end{array}$ & UUGGAA & cccccc & 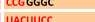 & A & \\
\hline Tyr & GUA & CCCGCGA & UA & GuUC & A[G+]ACUGGUA & GAAC & {$[\mathrm{m} 2,26]$} & GCGGA & cmuGuA & uccoc & Auguc & GCUGG & Im1YuICmIIm IIIIMIAJAU & $\operatorname{cog} g c$ & 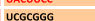 & $\begin{array}{l}A \begin{array}{l}A \\
A \\
A\end{array} C C A \\
C C A\end{array}$ & \\
\hline Ser & UGA & GCAGAGG & UG & GUUG & $A[G+] C U U G G C C A A$ & AGGC & {$[\mathrm{m} 2,2 \mathrm{G}]$} & CCGGA & [52C]UUGGAA & {$[$ [s2U] $\mathrm{CCG}$} & UUCUCCACUGGGGAGC & $6 G 6 G 6$ & [m1Y]U[cm][m1]][m1A]AU & cccuc & ccucusc & & \\
\hline Ser & scu & GCGGAGA & UG & Gccc & A[G+]UCUGGUA & CGGC & G & CGGGA & cugculttala & Ucccos & UUAGGCUCUGGGUAAC & CCGAG & uUCAAAU & CUCGG & ucuccec & & \\
\hline Ser & GGA & GCAGAGA & UA & gucu & $\mathrm{A}[\mathrm{G}+\mathrm{C} C \mathrm{CUGGA}$ & AGGC & {$[\mathrm{m} 2,2 \mathrm{G]}$} & UACGG & CUGGAAA & CCGGUA & UGAGGCUUUGGCCUCCCC & GGGGG & UUCAAAU & сcсcсc & ucucuace & G ce. & \\
\hline val & GAC & GAGUUCG & ug & Gucu & A[G+]UUGGCUA & UGAU & A & ccocc & CUGACAC & GGCGG & ugauc & GGGAG & UUCG[m1A]AU & cuccc & CGGACUC & A cc. & \\
\hline val & UAC & GGACCU[acta] & ug & Gucu & A[G] $]$ UGGGCUA & UGAC & A & UCGCC & CUUACAAA & GGGGA & GGGUC & $\sec G$ & uUcGau & $\operatorname{CCGGC}$ & UAGGUCC & A $C C A$ & \\
\hline furiosus & & & & & & & & & & & & & & & & & \\
\hline $\begin{array}{l}\text { Ala } \\
\text { Ala }\end{array}$ & GGC & 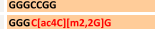 & UA & Gcue & $\begin{array}{l}\text { AGCCUGGUAU } \\
\text { A[G+]cCUGGUAU }\end{array}$ & $\begin{array}{l}G A G C \\
\text { GAGC }\end{array}$ & $\mathrm{G}$ & $\frac{\operatorname{coscc}}{\operatorname{ccscc}}$ & $\begin{array}{l}\text { UUGGCAA } \\
\text { CUICOMSUIGCAA }\end{array}$ & $\frac{G G C G G}{G G C G G}$ & $\begin{array}{ll}A G G C \\
A G G C C\end{array}$ & $\begin{array}{c}\cos 6 \theta \\
\cos \theta\end{array}$ & 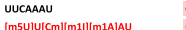 & 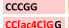 & cccGucc & A $c$ ca & \\
\hline Arg & $\begin{array}{l}\mathrm{OGC} \\
\mathrm{ccu}\end{array}$ & 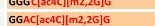 & $\begin{array}{l}\text { UA } \\
\text { UA }\end{array}$ & $\begin{array}{l}\text { Guc } \\
\text { Gccu }\end{array}$ & $\begin{array}{l}\text { A[t+]CCUGGGAU } \\
\text { A[G+CCCAGGAUA }\end{array}$ & $\begin{array}{l}\text { GAGC } \\
\text { GGGC }\end{array}$ & 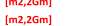 & $\frac{c \operatorname{coscc}}{\operatorname{cosgc}}$ & 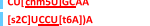 & $\frac{66666}{6 c 6 c 6 c}$ & $\begin{array}{l}\text { AGGGC } \\
\text { AGGuc }\end{array}$ & $\begin{array}{l}c 6666 \\
\text { c6G6G }\end{array}$ & 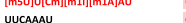 & $\begin{array}{l}\text { CClacaCjGG } \\
\text { ccccG }\end{array}$ & $\begin{array}{l}\text { cecosucec } \\
\text { ccosguce }\end{array}$ & $\begin{array}{ll}A & c C A \\
G & c C A\end{array}$ & \\
\hline Arg & ucu & GGGCCCG & UA & gccu & A[G+]CAGGAUA & GGGC & $\mathrm{G}$ & $\operatorname{cccscc}$ & 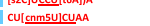 & GCcGG & AGGuc & ccGGG & 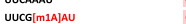 & cClac4CIGG & cGGGcece & $\begin{array}{ll}6 & \mathrm{CCA} \\
6 & \mathrm{cca}\end{array}$ & \\
\hline Arg & GcG & GCCCCGG & ug & sccu & AGCCUGGAU-A & GGGC & [m2G] & CGAGG & CUGCG[mimG]A & CCUL[Cm]G & AGGuc & CGGGG & UUCAAAU & CCCCG & ccoGGGCG & c $\mathrm{cCA}$ & \\
\hline Asp & guc & GCCCGGG & ug & GUGU & AGCCCGGCCUA & UCAU & [m2G] & CGGGA & CUGUCAC & ucces & CGAC & $\operatorname{ccGGG}$ & uUcaAaU & cCCGG & cccGGGC & $6 \mathrm{CCA}$ & \\
\hline cys & GCA & GCCGG[m2,2G]A & U[m1A] & GcCu & $\mathrm{A}[\mathrm{G}+\mathrm{AGGCC}$ & AGGC & {$[\mathrm{m} 2,2 \mathrm{G}] /[\mathrm{m2}, 2 \mathrm{Gm}]$} & GGGGA & CUGCAGA & uccec & uUuac & $\operatorname{ccGGG}$ & 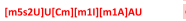 & CCCGG & ucccGGc & U CCA & \\
\hline Glu & cuc & $\mathrm{p}[2 \mathrm{H}-\mathrm{m} 7 \mathrm{G}] \mathrm{ccc}[\mathrm{ac} 4 \mathrm{C}][\mathrm{m} 2,2 \mathrm{G}] \mathrm{G}$ & ug & {$[\underline{2 H-m 2,7 \mathrm{Gm}] \cup G U}$} & $A[G+] c C C G G U C A A$ & UCAU & [m2G] & CGGGA & cunuculm16]A & Uccce & CGAC & $\operatorname{ccGGG}$ & uUcaAau & $\operatorname{cccos} \theta$ & CCGGGGC & A $C C A$ & \\
\hline Gin & cuG & AGccecG & ug & GUGU & $\mathrm{A}[\mathrm{G}+] \mathrm{c}[\mathrm{Gm}] \mathrm{m} \mathrm{CCAA}$ & GCAU & G & CGGGA & cU[acacm]UGGA & ucces & CGA[m5c] & {$[\mathrm{m5C}][\mathrm{Gm}] \mathrm{GGG}$} & uUcGaAu & ccccs & CGGGGCU & A $\mathrm{CCA}$ & \\
\hline Gln & UuG & AGcCCCG & ug & GUGU & $A[G+][G \mathrm{Gm}] \mathrm{GCCAA}$ & GCAU & G & CGGGA & CU[cnm5U]UGGA & UcccG & CGA[m5c] & [mSC]CGGG & UUCGImIA]AU & cClacaC] $] \mathrm{G}$ & CGGGGCU & A $C C A$ & \\
\hline Gly & $\mathrm{ccc}$ & GCGGUGG & UA & Gucu & A[G+]C[52C]UGGUCUA & GGAC & {$[\mathrm{m} 2,2 \mathrm{G]}]$} & $\operatorname{cogGc}$ & CUCCCAA & GCCGG & CGA[m5c] & [m5C]CGGG & uUCAAAU & $\operatorname{cccGg}$ & ccaccsc & A CCA & \\
\hline Gly & occ & $\mathrm{GCGGU}[\mathrm{m} 2,2 \mathrm{G}] \mathrm{G}$ & UA & GuCu & AGCCUGGUCUA & GGAC & G & cCACC & cuGCCAA & GGUGG & AGA[msc] & CCGGG & UU[Cm][m1]][m1A]AU & $\operatorname{cccGs}$ & сcACCGC & A CCA & \\
\hline Gly & ucc & GCGGUGG & UA & Gucu & $A[G+] c C U G G U C U A$ & GGAC & [m2G] & $\operatorname{ccGGC}$ & cu[enm5U]CC[m1G]A & GCCGG & CGAC & CCGGG & UUCAAAU & CCCGG & ccaccGc & A cc & \\
\hline \|e & GAU & GGGCCCG & ug & gcuc & $A[G+][[52]$ UGGUCA & GAGC & {$[\mathrm{m} 2,2 \mathrm{Gm}]$} & $\operatorname{cocccc}$ & CugAU[hn6A]A & GCGGG & AGGUC & CGGGG & UUCGAAG & ccclac4c]s & cGGGcec & A CCA & \\
\hline Ini & CAU & AGCGG[m2]GG & u[Gm] & $[\mathrm{m} 7 \mathrm{G}] \mathrm{GGC} / \mathrm{lcm}]$ & A[G+]CUAGGAG[Um] & {$[\mathrm{Gm}] \mathrm{ccc}$} & {$[\mathrm{m} 2,2 \mathrm{G}]$} & $\operatorname{coc} 6 \theta$ & CUCAUAA & $\operatorname{cocos} \theta$ & $A G G[x \in] C$ & CGAGG & {$[m 552 U] U[\mathrm{~cm}][m 11][m 1 \mathrm{~A}] \mathrm{AU}$} & cCUCG & बccecceu & A CCA & \\
\hline Leu & CAG & GCGGGGG & uu & GCCG & A[G+][[52C]UGGUCAA & AGGC & {$[\mathrm{m} 2,26 \mathrm{~m}]$} & $\operatorname{CGGGA}$ & UUCAGGG & UCCCG & UcCCGUAGGGGUUC & CGGGG & uUCAAAu & ccccs & $\operatorname{coccccsc}$ & A CCA & \\
\hline Leu & UAA & GCGGGGG & ug & CCCG & AGCCUGGCCAA & AGGG & G & $\operatorname{ccG} 6 A$ & CUUAAGA & UCCGG & UGCCGUAGGGCUGC & GCGGG & uUcGaAu & $\operatorname{cccGc}$ & coccctec & A $C C A$ & \\
\hline Leu & UAG & GCGGGGG & uo & GCCG & A[G+] $]$ CCUGGUCAA & AGGC & {$[\mathrm{m} 2,2 \mathrm{Gm}]$} & CGGGA & UU[EnmSU]AGGG & Uccecs & UCCCGUAGGGGUUC & 06666 & UUCAAAU & CCCCG & cccccsec & A CCA & \\
\hline Lys & cuu & GGGCCGG & UA & scuu & AGCCUGGUU-A & GAGC & {$[\mathrm{m} 2,2 \mathrm{Gm}]$} & GCGGA & CUCUUU[ms2t6a]A & UcCGC & AGGUC & $6 G 6 G 6$ & {$[m 5 U] U\left[c_{m}\right][m 11][m 1 A] A U$} & $\operatorname{ccccc}$ & сcбGscc & $6 \mathrm{cc}$ & \\
\hline Met & CAU & $\operatorname{Gcc} G G[m 2,2 \mathrm{G}] \mathrm{G}$ & UA & GCUU & AGcCUGGUCA & AAGC & {$[\mathrm{m} 2,2 \mathrm{Gm}]$} & [msclccGG & CU[Cm]AU]hn6A]A & cCGGG & AGA[IXU]C & $\operatorname{cog} 6$ & [m5s2u]U[cm] & ccClac4C]G & ceccegce & A CCA & \\
\hline Phe & GAA & GGGGCGG & UA & gcuc & $A[G+][52 c] \cup G G G A$ & GAGC & A & $\operatorname{ccc} 6 A$ & CUGAA[mimG]A/[Am] & Ucces & Guguc & 66666 & UU[Cm][m1]][m1A]AU & cccec & $\operatorname{ccscccc}$ & A CCA & \\
\hline Pro & UGG & GGGGCCG & UA & GGGU & AGCUUGGCCCA & uccu & [m2G] & C6G6C & 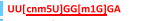 & GcClac4C]G & UGAC & $\operatorname{ccc6s}$ & uUcAAAU & $\operatorname{ccccos}$ & $\operatorname{coscccc}$ & A $\mathrm{CCA}$ & \\
\hline Ser & Gcu & GCCGCGG & UA & GcCu & $A[G+] C C U G G U A$ & GGGC & {$[\mathrm{m} 2,2 \mathrm{~mm}]$} & $\cos 6 \mathrm{C}$ & CUGCU[t $\left.t^{6} \mathrm{~A}\right] \mathrm{A} /[\mathrm{Am}]$ & बCCGG & | UGGGCGUGGUCCCGC & c6666 & uUCAAAU & $\operatorname{coccc} \theta$ & $\operatorname{cccccgcc}$ & 6 cCA & \\
\hline Ser & GGA & GCCGGGG & UA & sccu & AGcCAGGG-A & AGGC & G & CGGGC & CUGGA[mimG]A & $\mathrm{G} /[\mathrm{m} 2,2 \mathrm{G}] \mathrm{cccG}$ & UGGGGGUUCGCCCAC & CGGGG & UUCAAAU & $\operatorname{ccccc}$ & coccGGac & G cc- & \\
\hline Ser & UGA & GccGG[m2G]//m22G]A & U//Um][n & A] GcCu & AGcCuGGU-A & GGGC & {$[\mathrm{m} 2,2 \mathrm{Gm}]$} & CGGGC & cuUGAlim62)/(mimG]A & GCCCG & [ [Um]GGGGGUL & CGGGG & [m5U]/[m5s2u]UCAAAU & ccccs & ucccGGe & $6 \mathrm{cc}$. & \\
\hline Thr & GGU & GccccsG & ug & gcuc & $A[G+] C C /[s 2 c] \cup G G \cup A$ & GAGC & {$[\mathrm{m} 2,2 \mathrm{~m}]$} & GcCGC & UUGGUIEAG][hnGA]A & GCGGC & AGG[XU]C & $\operatorname{ccc6g}$ & $[\mathrm{m5U}] /[\mathrm{m} 5 \mathrm{~s} 2 \mathrm{U}] \mathrm{U}[\mathrm{cm}][\mathrm{m} 1]][\mathrm{m}$ & $\operatorname{coc} \theta$ & $\mathrm{CCG} /[\mathrm{Gm}] \mathrm{GGGC}$ & U CCA & \\
\hline Thr & ugu & GCCCGGG & UA & sccu & AGcCUGGUG & GGGC & {$[\mathrm{m} 2,2 \mathrm{Gm}]$} & GGGGA & CUI[snm5U]GU[hn6A]A & uccec & AGGUC & GCGGG & uUCAAAU & cccoc & cccGGGC & U CCA & \\
\hline $\operatorname{Trp}$ & ccA & GGGGGCG & ug & GUGU & AGCCUGGUCCA & UCAU & c & GCGGG & CuccAG/[mimG]A & {$[\mathrm{cm}] \mathrm{c}[\mathrm{cm}][\mathrm{Gm}] \mathrm{C}$} & [GaA[m5C] & CGGGG & UU[Cm][m1]][m1A]AU & $\operatorname{cccccs}$ & csccecc & A cCA & \\
\hline val & $G A C$ & GGGCCCG & ug & Gucu & $A[G+] A C \cup G G U \cup A$ & UGAC & {$[m 2,26]$} & cacec & CUGACAA & GGUGG & AGGuc & $\operatorname{cog} 6 \sigma_{0}$ & uUCAAAU & $\operatorname{cocccs}$ & cGGGccc & A cCA & \\
\hline $\begin{array}{c}\text { Val } \\
\text { S. acidocaldarius }\end{array}$ & UAC & GGGCCCG & UG & Gucu & A[G+]CUGGUUA & UGAC & & ccocec & cuUACGA & GGCGG & AGGUC & cGGGG & UUCGImIAAAU & ccclacact] & cGGocecc & A CCA & \\
\hline Ala & GGC & GGGCCGG & UA & gcuc & $A[G+] c[\mathrm{~cm}]$ UGGAA & GAGU & {$[\mathrm{m} 2,2 \mathrm{G}]$} & cGUGG & Uuggcau & CCACG & AGGUC & CCGGG & uUCAAAU & CCCGG & cceGGucc & $A \quad C C A$ & \\
\hline Ala & UGC & GGGCCGG & UA & gcuc & $A[G+][C[C m] \cup G G A-A$ & GAGU & {$[m 2,26]$} & cuUcG & {$[\mathrm{Cm}] \cup[\cup \mathrm{m}] \mathrm{GCAA}$} & ClacAC]GAC & AGGUC & CCGGG & UUCAAAU & cCCGG & ccGGucc & $C A$ & \\
\hline Asn & GUU & GCCGCGG & UA & Gcuc & AGUUGGCA & GAGC & $\mathrm{G}$ & CCGGG & cugu & $\operatorname{ccccos}$ & UGGU & GGUGG & UCCGAGU & CCACC & ccGCGGC & $\mathrm{G}$ & \\
\hline Asp & guc & GClacaClocGG & $U[m 1 A$ & Im2,2G]UCU & A[G+]CGGUCUA & GGAIUm & {$[\mathrm{m} 2,2 \mathrm{G]}]$} & $G G G G C$ & CUGUC $[\mathrm{m} 1 \mathrm{G}) /[\mathrm{imG}]$ & Gcccu & UGA[m5C] & {$[\mathrm{msc}$} & [ [22U]U] $\mathrm{cm}][\mathrm{m}]$ & $\operatorname{ccccos}$ & cCGI[Cm]GG[m5C & G & \\
\hline GIn & vog & AGCCGGG & uc & Gucu & A[G+]c[Gm]GUCAA & G[Gm]AU & {$[\mathrm{cm}]$} & CAGGG & cu[Um]/[s2Um]UG $[\mathrm{m} 1 \mathrm{G}] \mathrm{c}$ & CCCUG & GGALmsc] & [m5CIAGGG & uUcGaGU & $\operatorname{ccc}[\mathrm{Um}] \mathrm{G}$ & cccosc[Um] & A & \\
\hline Glu & cuc & GCCGCGG & UA & [m226]GUAU & $\mathrm{A}[\mathrm{G}+] \mathrm{CcC}[\mathrm{Gm}] \mathrm{GUC}-\mathrm{A}$ & guau & {$[\mathrm{m} 2,2 \mathrm{G]}]$} & [m5C]6GGC & [ [Cm]UCUCAA & GcccG & UGA[m5C] & {$[\mathrm{m} 5 \mathrm{C}] \mathrm{C}[\mathrm{Gm}] \mathrm{GG}$} & [s2U]U[ $[\mathrm{cm}][\mathrm{m} 11][\mathrm{m} 1 \mathrm{~A}] \mathrm{AU}$ & $\operatorname{ccccs} \theta$ & ccocGGC & A & \\
\hline Glu & uuc & GCCGCGG & UA & [m2,2G]UAU & $\mathrm{A}[\mathrm{G}+] \mathrm{CCC}[\mathrm{Gm}] \mathrm{GUCAA}$ & guau & {$[\mathrm{m} 2,2 \mathrm{G]}]$} & {$[m 5 c] 6 G 6 c$} & C CUUUCGA & GCCCG & UGA[m5c] & $[\mathrm{msc}] \mid \mathrm{cm}] \mathrm{GGG}$ & UUCAAAU & CCCGG & $\operatorname{ccGcGGC}$ & & \\
\hline Giy & Gcc & GCGGCCG & UA & Gucu & A[G+]CCUGG[Am]UUA & GGAC & {$[\mathrm{m} 2,2 \mathrm{G]}]$} & ccusc & cuGCCAC & GCAGG & AGGGXU]C & $\mathrm{C}[\mathrm{Cm}] \mathrm{GGG}$ & [s2U]U[ $[\mathrm{cm}][\mathrm{m} 11][\mathrm{m} 1 \mathrm{~A}] \mathrm{AU}$ & $\operatorname{cccGs}$ & CGGUCGC & $\mathrm{A}$ & \\
\hline Leu & CAA & GCGGGGG & UG & cccG & A[G+]CUGGUCAA & AGGG & G & GCGGA & CUCAAGA & uccGC & UGGCGAAGGCCU[Am] & GCGGG & UUCAAAU " & cccGu & $\operatorname{coccccsc}$ & A & \\
\hline Leu & CAG & GCGGGGG & UG & cccs & AGCIAM]AGGUCAA & AGGG & {$[\mathrm{m} 2 \mathrm{~g}] / \mathrm{m}$} & UCGGG & {$[\mathrm{Cm}] \mathrm{U}[\mathrm{C} \mathrm{c}] \mathrm{AG}[\mathrm{m} 1 \mathrm{G}] \mathrm{C}$} & CCCGA & UGGUGUAGGCCUGC & G[UM]GGG & [s2U]UCAAAU & CCCAC & $\operatorname{ccccccsc}$ & A & \\
\hline Leu & GAG & GCGGGGG & UG & CCCG & $A[G+c[C[A]] A G G \cup C A A$ & AGGG & {$[\mathrm{m} 2,26]$} & GCGGA & {$[\mathrm{cm}] \cup \underline{\mathrm{GAG}[\mathrm{m} 1 \mathrm{G}] \mathrm{c}}$} & uccoc & UGGUGUAGGCCUGC & G[Um]GGG & [s2U]U|cm|[m11]| & CCCAC & $\operatorname{coccccsc}$ & A & \\
\hline Leu & UAA & GCGC & UG & cccG & AGGUCAA & AGGG & G & GCGGA & CUUAAGA & UCCGC & UGGCGUAGGCCMUIm & & UU[cm]]m1]][n & CCCAC & $\operatorname{coccccsc}$ & A & \\
\hline Leu & UAG & GCGGGGG & UG & cccG & AGCAAGGUCAA & AGGG & G & UCGGG & {$[\mathrm{cm}] \mathrm{U}[\mathrm{s} 2 \mathrm{Um}] \mathrm{aG}[\mathrm{m} 1 \mathrm{6}] \mathrm{C}$} & CC[acac]GA & UGGUGUAGGCCUGC & GUGGG & UUCAAAU & сCCAC & $\operatorname{coccccsc}$ & A & \\
\hline Ini & CAU & AGCGGCG & U[mAA] & {$[\mathrm{m} 2 \mathrm{G}] \mathrm{GGA}$} & A[G+]CCUGGUA & ucce & {$[\mathrm{m} 2,2 \mathrm{~mm}]$} & CAl[m]GG & ICM]UCAUAA & cccus & AgGuC & CC[Um]GG & {$[\mathrm{s} 2 \mathrm{U}] \mathrm{U}[\mathrm{cm}][\mathrm{m} 1 \mathrm{1}][\mathrm{m}$} & $\mathrm{C}[\mathrm{Cm}] \mathrm{AGG}$ & сөсçсcu & A & \\
\hline Pro & UGG & GGGGCCG & UA & Gucu & AGCUUGG[Am]CUA & GGAU & {$[\mathrm{m} 2,2 \mathrm{~g}]$} & CCAGG & cUUGG[m1G]c & couse & UG & $\operatorname{cog} 6 \theta$ & UUCAAAU & $\operatorname{cccos}$ & cosccece & A & \\
\hline Phe & GAA & GcCGcCG & UA & scuc & AGCCCGGGA & ${ }_{G A G[C m]}$ & {$[\mathrm{m} 2,2]$} & $\operatorname{coc} \theta 6$ & CUGAA[mimG]A & CCGGG & uo & $\cos$ & $[\mathrm{s} 2 \mathrm{U}] \mathrm{U}, \mathrm{Cm}][\mathrm{m} 11][\mathrm{mL} \mathrm{A}] \mathrm{GU}$ & ccccs & cGGCGGC & A & \\
\hline Thr & gGu & Geccects & UA & gcuc & $\mathrm{AG}^{-}-(-3)$ & GAGC & {$[\mathrm{m} 2,2 \mathrm{~g}]$} & vuccec & CUGGUItGA]A & GGCAA & AGS & $\cos c$ & uUCAAAU & $\operatorname{cccos} \theta$ & $\operatorname{cccccosc}$ & u & \\
\hline Trp & ccA & $G G$ & $U\left[m A^{\prime A}\right]$ & [m2G]]UC & IA & GAGU & {$[\mathrm{m} 2,2$} & $\operatorname{cccGG}$ & 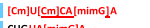 & {$[\mathrm{cm}] \mathrm{cos} \theta$} & UgGuc & $\operatorname{cog}$ & uUCAGGU & $\operatorname{ccccc} \theta$ & ugGscce & A & \\
\hline Tyr & GUA & $\mathrm{ccc}$ & UA & gcuc & ivg & GAGC & {$[\mathrm{m} 2,2 \mathrm{Gm}]$} & $\operatorname{coc} 6 \theta$ & CuguA[mimG]A & $\operatorname{ccGGG}$ & ugGuc & $\mathrm{CG}[\mathrm{Gm}] \mathrm{GG}$ & 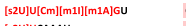 & ccccG & CGGCGGG & A & \\
\hline Ser & UGA & Gc & ug & $\mathrm{cc}$ & AG & AGGG & {$[\mathrm{m} 2,2 \mathrm{2G}]$} & [msc]UGGG & cu[mchm5Um]GA[mimg]A & $\sigma c$ & UAGGGUUAUCCCU[m2,2G]C & G[Um]GGG & [SZ2]UCAAAAU & cCCAC & $\operatorname{cocccosc}$ & G & \\
\hline Ser & GGA & GCCGGGG & UG & CCCG & AGUGGACUA & AGGG & G & CUGGC & CUGGAGA & GCCAG & UGUGGAUCUUCCACGGC & GCGGG & UUCAAAU & $\operatorname{cccGc}$ & CccCGGC & 6 & \\
\hline val & GAC & GGGCCCG & uc & [m2G]UCu & $A[G+][C[C m] U G G U U-A$ & GGA[Cm] & {$[m 2,26]$} & cusce & {$[\mathrm{Cm}] \cup \underline{\mathrm{GAC}}[\mathrm{m} 1 \mathrm{G}] \mathrm{C}$} & GGCAG & AAA[x $\underline{x \in] C}$ & {$[\mathrm{~m} 5 \mathrm{cc}][\mathrm{Um}] \mathrm{GGG}$} & {$[\mathrm{s} 2 \mathrm{U}] /\left[\mathrm{m}^{\mathrm{x}} \mathrm{s}^{\mathrm{U}} \mathrm{]}, \mathrm{cm}\right][\mathrm{m1} 1][\mathrm{m1}$} & CCCAG & cGGGcce & A & \\
\hline
\end{tabular}

FIGURE 1. Compilation of modified tRNA sequences from S. acidocaldarius, M. maripaludis, and $P$. furiosus. Red nucleotides indicate fragments obtained by RNase T1, and/or RNase A, and/or RNase U2 digestion, while black nucleotides represent regions that could not be analyzed. Nucleotides in gray are modified nucleotides with a mass corresponding to several possible modifications.

both contain, after the conserved U8, U9 instead of the very common $\mathrm{R} 9(\mathrm{R}=\mathrm{A} / \mathrm{G})$. This is also the case in Thermoplasma acidophilum, a thermo-acidic Euryarchaeon where $s^{4} U 8$ and $s^{4} \cup 9$ have been detected (Tomikawa et al. 2013). This occurrence of two consecutive Us at positions 8 and 9 is surprisingly accompanied by an unusual G38 opposite to U32 in the anticodon loop (especially with a CAG anticodon). Although we could not detect $s^{4} U$ at either position 8 or 9, the nucleoside analysis (Supplemental Figs. S2, S3) confirms the presence of $s^{4} U$ in both $M$. maripaludis and $P$. furiosus. An analysis of the GtRNAdb shows that these correlations stand out in Euryarchaeota and Thaumarchaeota (Chan and Lowe 2009, 2016). The D-stem presents also some particularities like a preference for
G10-Y25 and Y13-G22 with the central two base pairs maintained as Watson-Crick. It is likely that some, if not all, of the uridines at positions 13, 22, and 25 of the Dstem and position 39 of the anticodon stem (AC-stem) are pseudouridines $(\Psi)$ which cannot be differentiated from $U$ by mass spectrometry. Moreover, the $\mathrm{AC}$-stem has a pronounced preference for a G30-C40 pair, while in other tRNAs, especially of mesophilic organisms, a A30-U40 pair is present (Marck and Grosjean 2002). There are seven residues in the $\mathrm{AC}$ - and T-loops with the conserved residues $\mathrm{U} 33$ and the favored C32/A38 opposition in the anticodon loop. In the Sulfolobales clade of the Crenarchaeota, the tRNA-Cys(GCA) has an unusual C33 (together with G27oU43), but unfortunately we could not isolate 


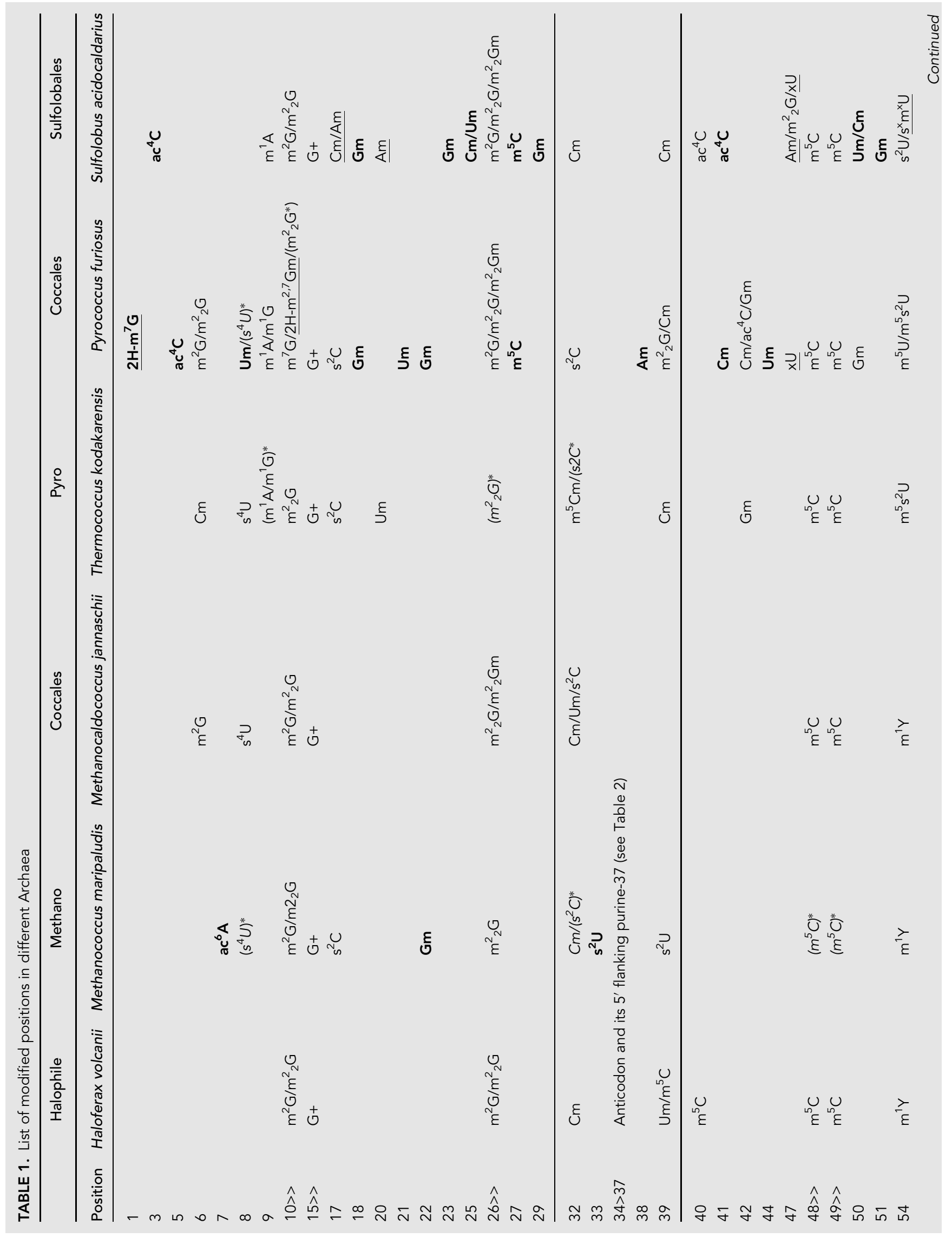




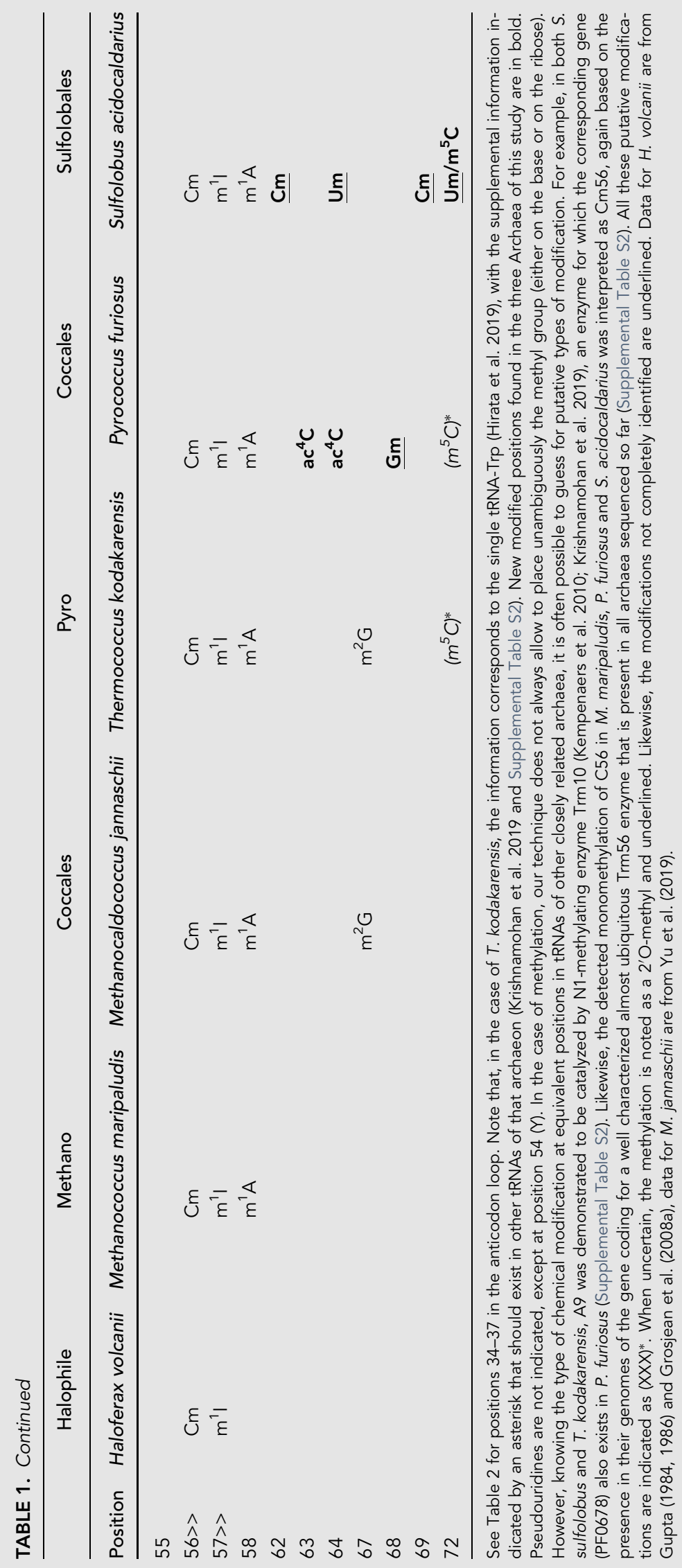


those tRNAs. The T-loop is closed by an invariant G53-C61 pair with always the possibility to form a U54/A58 trans Watson-Crick/Hoogsteen stacking against it. The trans Watson-Crick/Hoogsteen between U8 and A14 is always present and triple formation with $A 21$ is possible in the large majority of sequences. Interestingly, 15-48 is always a G15-C48 pair (Supplemental Fig. S11A) that stacks with the invariant $A 60$ (from the T-loop). In three tRNA sequences (lle, elongator Met, and Thr) of $P$. furiosus, residue 60 is $G$ instead of the usual $U$, and is preceded by $A 59$, which forms a rare combination. $\mathrm{C} 48$, as expected, is often methylated on $\mathrm{C} 5\left(\mathrm{~m}^{5} \mathrm{C}\right)$; in which case, the methyl group would be in the tRNA core and in the neighborhood of the charged formamidino group of $\mathrm{G} 15\left(\mathrm{G}^{+}\right)$. The positive charge on $\mathrm{G} 15$ points in a cavity surrounded by three negative phosphate groups from residues 7, 14, and 15. Altogether, these peculiarities correspond to tRNAs well stabilized, even in the mesophilic M. maripaludis.

\section{New modified positions}

Table 1, Figure 1, Supplemental Figure S10, and the corresponding Supplemental Table S2 list all the modified nucleotides we have detected, among them several are present at newly identified positions (mostly methylations and acetylations in the two thermophilic archaea). In eukaryotic tRNAs, the $\mathrm{m}^{2}{ }_{2} \mathrm{G}$ modification is exclusively found at position 26 (exceptionally at position 27) at the interface between the D- and AC-stems (Machnicka et al. 2014), while in archaeal tRNAs, it is present at many other locations. The $\mathrm{m}^{2}{ }_{2} \mathrm{G} 10$ is observed when residue 25 is a $U$, in which case the $\mathrm{m}^{2}{ }_{2} \mathrm{G}$ modification stabilizes the G10oU25 wobble pair (discussed in Urbonavicius et al. 2006). Similarly, the 26-44 pair displays a frequent $\mathrm{G} 26$ modification ( $m^{2} G, m^{2}{ }_{2} G$ but also $m^{2}{ }_{2} G m$ ), forming either $G 260 U 44$ or G26-A44 pairs (Supplemental Fig. S11D), rarely G26C44 (with a slight bias toward $\mathrm{m}_{2}^{2} \mathrm{G}$ at position 26 when pairing with U44, especially for the long-arm tRNAs Leu and Ser). Surprisingly, in tRNA-Ser(GGA) of $P$. furiosus, MS/MS data and T1 cleavage analysis (Supplemental Table S1) indicate the presence of $\mathrm{m}^{2}{ }_{2} \mathrm{G}$ at positions 39, which would induce a pronounced propeller-twist of the $\mathrm{C} 31=\mathrm{m}_{2}^{2} \mathrm{G} 39$ pair (as seen in Supplemental Fig. S11D). A similar situation exists for $\mathrm{m}^{2}{ }_{2} \mathrm{G} 6-\mathrm{C} 67$ in the amino acid stem. Only thermophilic archaea present the triple methylation $\left(\mathrm{m}_{2}^{2} \mathrm{Gm}\right)$ on both the base and the ribose. Such "doubly" modified nucleosides (xNm) are hallmarks of hyperthermophilic tRNAs (McCloskey et al. 2001; Grosjean et al. 2008b; Hori et al. 2018).

In tRNAs of both Bacteria and Eukarya, the positively charged $m^{7} G$ is often found at position 46 in the variable region (Machnicka et al. 2014). $\mathrm{m}^{7} \mathrm{G}$ has been identified in unfractionated bulk tRNAs of two thermophilic archaea, Thermoproteus neutrophilium and Thermoplasma acidophilium (Edmonds et al. 1991). Recently $\mathrm{m}^{7} \mathrm{G}$ was located at position 49 of $T$. acidophilum tRNA-Leu (UAG) (Tomikawa et al. 2013). Here, we report the presence of $m^{7} G$ at position 10 of tRNA-Met (CAU) of $P$. furiosus. We suggest also the presence of a reduced neutral form of $2 \mathrm{H}-\mathrm{m}^{7} \mathrm{G}$ at positions 1 and 10 of tRNA-Glu (CUC) (for position 10 we suggest an unexpected and unique case of tri-methylated $2 \mathrm{H}-\mathrm{m}^{2}{ }_{7} \mathrm{Gm}$ ). These suggestions are based on the following observations. The monomethylated nucleotide at position 10 of tRNA-Met' has a mass of 359 Da with a neutral loss of $165 \mathrm{Da}$ that is characteristic of a normal $m^{7} G$, while at position 1 of tRNA-Glu, the methylated nucleotide has a mass of $361 \mathrm{Da}$ (Supplemental Fig. S4), which could correspond to the reduced form of $m^{7} \mathrm{G}\left(2 \mathrm{H}-\mathrm{m}^{7} \mathrm{G}\right)$ (Supplemental Fig. S4D; Wintermeyer and Zachau 1975). The same reduced form exists for $2 \mathrm{H}-\mathrm{m}^{2}{ }_{7} \mathrm{Gm}$ at position 10 of tRNA-Glu. The accuracy is less than $0.05 \mathrm{Da}$; however, in the absence of standard substance to compare against, these suggestions are still tentative. The presence of an $m^{7} G$ derivative at position 1 of an archaeal tRNA would indeed be remarkable. Usually, such guanosine derivatives are found in the form of a positively charged cap-like structure protecting the tRNA against 5'-exonucleolytic degradation (see for example Ohira and Suzuki 2016). In $\mathrm{m}^{7} \mathrm{G}$ cap, the $5^{\prime}$ extremity is a $5^{\prime} \mathrm{OH}$, while our MS/MS data show a classical 5'P extremity on the $P$. furiosus tRNA-Glu (see Supplemental Fig. S4B, which corresponds to the MS/MS spectrum of the 5'-end of tRNA-Glu where, in the ion series $c, c 1$ corresponds to $p 2 H-m^{7} G$ ). A putative protecting role of such terminal $m^{7} \mathrm{G} p$ against specific exonucleolytic degradation processes remains to be demonstrated in Archaea.

Very recently, Sas-Chen et al. (2020) published a thorough analysis of $\mathrm{ac}^{4} \mathrm{C}$ modifications in rRNAs and tRNAs across phylogeny including several archaeal species. They found high concentrations of $\mathrm{ac}^{4} \mathrm{C}$ in the hyperthermophiles Thermococcus kodakarensis, $P$. furiosus, Thermococcus sp. AM4, and S. solfataricus, with a preference for CCG sites, the modified $C$ being the middle C. Residues $\mathrm{ac}^{4} \mathrm{C}$ most certainly contribute to the stabilization of base pairs (Kawai et al. 1992). In this work we identified $13 \mathrm{ac}^{4} \mathrm{C}$ modifications in the isolated tRNAs (Table 1; Fig. 1) and all, except the one at the wobble position 34 of tRNA-GIn ( $\mathrm{cc}^{4} \mathrm{CmUG}$ - see below), are found in the middle position of a CCG motif within a stem. For example, in S. acidocaldarius, $a c^{4} \mathrm{C}$ is found at position 41 of the AC-stem of tRNA-Leu(UAG) and at position 40 of tRNAAla(UGC). m5C40 is found in tRNA-lle of $H$. volcanii (Grosjean et al. 2008a). In position 40, the modification cannot be a ribose methylation ( $\mathrm{Cm} 40$ ) because the $\mathrm{O}^{\prime}$ (C40) is functionally engaged in $\mathrm{H}$-bonds with the conserved A1339 of the $16 \mathrm{~S}$ rRNA during the P state of translation (Selmer et al. 2006; Watson et al. 2020). Indeed, the base pairs of the AC-stem 30-40 and 29-41 are both involved in contacts with, respectively, G1338 and A1339 of the 16S rRNA in the P state (Supplemental Fig. S12A, 
B). In tRNA-Met'(CAU) of S. acidocaldarius, residue G29 pairing with $\mathrm{C} 41$ is methylated but in this case the 2'-hydroxyl group is far enough from G1338 and therefore can accommodate a methyl group, leading to a final assignment of 2'O-methyl G29 (Gm). In S. acidocaldarius, we found a $\mathrm{m} 5 \mathrm{C}$ residue at position 72 in the acceptor stem of tRNA-Asp(GUC), while at the same position in tRNAGln(UUG), an undetermined monomethylated U72 (indicated as Um) was found. Residue $\mathrm{m} 5 \mathrm{C} 72$ has been already reported in S. solfataricus tRNA-Glu/-Gly/-Met (Wagner et al. 2004), as well as in tRNA-Cys and tRNA-Thr of humans (Haag et al. 2015). Residue $\mathrm{m} 5 \mathrm{C}$ is quite common at positions 40 (see above), 48, 49 of tRNAs in both Eukarya and Archaea (Machnicka et al. 2014). Worth to note is that, in tRNAs of S. acidocaldarius (and to a lower extent of $P$. furiosus), many residues are monomethylated all over the molecules. Some are catalyzed by site-specific protein-only methyltransferases while others are catalyzed by Fibrillarin-C/D box sRNP guide machinery acting on specific intron-containing pre-tRNAs (Gaspin et al. 2000; Omer et al. 2000; Clouet d'Orval et al. 2001; Dennis et al. 2001). From the database maintained by Todd Lowe (provided at http://lowelab.ucsc.edu/snoRNAdb/), this enzymatic machinery in $S$. acidocaldarius could target sitespecific methylations to tRNA-Gly(CCC) at C50 in the Darm (Tang et al. 2005; Zago et al. 2005) and to tRNA-GIn (UUG) at U34 and G18 of the AC- and D-loops, respectively (see also Ziesche et al. 2004), a situation indeed observed in the present study. However, in S. acidocaldarius, a few other observed monomethylated nucleotides remain orphan and await corresponding snoRNAs or stand-alone specific methyltransferases to be identified (Table 1; Supplemental Table S2, they are indicated as Xm). Likewise, in tRNAs of $P$. furiosus, several positions were predicted to be methylated via the Fibrillarin-C/D box machinery: tRNA-Trp(CCA) at C32, C34, C39, tRNA-Leu(UAA) at G47, tRNA-Leu(CAA) at C34, tRNA-Gln at C16, tRNA-Val and tRNA-Gly at G26 and tRNA-Asp(GUC) at U35 (http ://lowelab.ucsc.edu/snoRNAdb/). However, although we do observe $\mathrm{Cm} 34, \mathrm{Am} 38$, and $\mathrm{m}^{2}{ }_{2} \mathrm{Gm} 26$ in some tRNAs, the other putative methylated positions listed above were presently not detected in the set of tRNAs we analyzed.

In M. maripaludis, most modified nucleotides were expected, except a methylated $G 22(\mathrm{Gm})$ in tRNA-Ala (UGC) and an unidentified adenine derivative in the acceptor stem of tRNA-Val(GAC). The corresponding nucleoside $A^{*} 7$ displays a mass of 309.1 Da corresponding to either hypermodified $\mathrm{m}^{6}{ }_{2} \mathrm{Am}$ or monomodified N6-acetylA. We tend to favor the latter $\left(a c^{6} A\right)$, since such acetylated adenosine has been discovered in another methanogen (Sauerwald et al. 2005) with its location, however, tentatively assigned to residue 37. In M. maripaludis, a mass corresponding to $f^{6} \mathrm{~A} 37$ was found instead in tRNA-Asp (GUC) (see below). Intriguingly, in tRNA-Leu(UAG), the C32 is unmodified but U33 of the AC-loop, a very rarely modified conserved residue, is thiolated $\left(s^{2} U\right)$ (Supplemental Fig. $\mathrm{S6}$ ). An $\mathrm{s}^{2} \mathrm{U} 33$ has already been found in trypanosomid mitochondrial tRNA-Trp(CCA) (Crain et al. 2002), where the stop codon is translated as Trp (Alfonso et al. 1999). The probability to find site-specific $2^{\prime} \mathrm{O}$-methylations guided by snoRNA in M. maripaludis, is meager as the frequency of occurrence of potential intron-containing tRNA targets in mesophilic archaea is much lower than in the hyperthermophilic archaea (Sugahara et al. 2008).

\section{Modifications in D-loops}

In mesophilic bacterial and eukaryotic tRNAs, U17 as well as a few other Us at positions 16, 20, and 20a of the D-loop, are usually modified to dihydrouridine (D). In thermophilic bacteria and hyperthermophilic archaea, this thermolabile dihydrouridine $D$, is rare or even totally absent (Edmonds et al. 1991), while in psychrophilic bacteria $D$ is abundant (Dalluge et al. 1997). From these observations, Dalluge and coworkers (1977) suggested an interesting functional role for $D$ in the maintenance of a certain degree of conformational flexibility in tRNAs, especially important to organisms growing at low temperatures where the dynamics of thermal motions of tRNAs are severely compromised. Unexpectedly, in tRNAs of $M$. maripaludis and of $P$. furiosus we found 2-thiocytidine at position 17 (Table 1; Fig. 1), a situation found also in the hyperthermophilic tRNATrp of T. kodakarensis (Hirata et al. 2019). However, in S. acidocaldarius, position 17 contains instead a methyl group on either $\mathrm{C}$ or $\mathrm{A}$, most probably a 2'-O-methyl (discussed above) (Table 1). Usually, $\mathrm{s}^{2} \mathrm{C}$ and $\mathrm{Cm}$ are found at position 32 of anticodon loops (Jühling et al. 2009; Boccaletto et al. 2018). Thiolation of pyrimidines and methylation of 2'-O-ribose of nucleotides are known to favor stacking, thus limiting local flexibility of the RNA (Plesiewicz et al. 1976; Larsen et al. 2015), a property that is obviously important in organisms thriving at high temperatures.

In most crystal structures, residue 17 bulges out of the tRNA core structure and is exposed to solvent. In addition, residues 16 and 17 are in the vicinity of two other bulging residues from the T-loop, 59 and 60 , and modifications in the D-loop may limit the tendency of residues 16 or 17 to bulge out of the loop. The locations of residues 16 or 17 , either within or outside the tRNA core, may influence interactions between other residues in the T-D environment. When residue 16 is a pyrimidine, it is often observed that it forms a pair with residue 59 , especially when 59 is also a pyrimidine. However, in the present archaeal tRNAs, residue 59 is always $A$ and residue 60 is mostly U. In that case, a couple of crystal structures show A59 stacked on G15$\mathrm{C} 48$ and $\mathrm{U} 60$ forming an $\mathrm{H}$-bond between N3(U60) and the phosphate group between the two invariant G18G19 of the D-loop (see for example PDB entry 2DU3, Supplemental Fig. S12C; Fukunaga and Yokoyama 
2007). As stated above the modified $G$ bearing a positively charged formamidino group $\left(\mathrm{G}^{+}\right.$, archaeosine), a hallmark of archaeal tRNAs, also contributes to the global stability of the 3D-core of tRNA. In Bacteria and Eukarya, nucleotide 15 is never modified.

\section{Modifications in TYC-loops}

Nucleotide U54 is nearly always modified to thymine or 5-methyluridine $\left(\mathrm{m}^{5} \mathrm{U}\right)$ in Eukaryotes and Bacteria (Machnicka et al. 2014). However, in most Archaea (mainly Euryarchaeota), a 1-methylpseudouridine $\left(m^{1} \Psi\right)$ is generally found instead (Pang et al. 1982; Gupta 1984; McCloskey et al. 2001; Chatterjee et al. 2012; Yu et al. 2019). Such a modification adds a methyl group to the pseudouridine $(\Psi)$ at the free $N 1$ atom, a position structurally equivalent to the $\mathrm{C} 5$ atom of T54. In the case of Ignococcus hospitalis, a crenarchaeon thriving at temperatures up to $100^{\circ} \mathrm{C}$, $\mathrm{m}^{1} \Psi 54$ was shown to be further hypermodified into $s^{4} m^{1} \Psi$ (Rose et al. 2020). The sulfur atom at position 4 in $\Psi 54$ is structurally equivalent to the sulfur atom at position 2 of U54 (see Fig. 6 of Rose et al. 2020). In a few other archaea belonging to the thermococcales clade among the Euryarchaeota, as $P$. abyssi, P. furiosus, and T. kodakarensis, the bacterial-like $\mathrm{m}^{5} \mathrm{~s}^{2} \mathrm{U}$ has been identified instead (Kowalak et al. 1994; Urbonavicius et al. 2008; Hirata et al. 2019; for review, see Hori et al. 2018).

In this work, we confirm the presence of $\mathrm{m}^{1} \Psi 54$ in the mesophilic M. maripaludis, and in the hyperthermophilic $P$. furiosus a mix of $m^{5} \cup 54$ and $m^{5} s^{2} \cup 54$ (Supplemental Figs. S2 and S9). For $P$. furiosus, the result is consistent with the fact that the 2-thiolation process occurs after 5methylation of U54 and 1-methylation of A58 (Shigi et al. 2006). For $S$. acidocaldarius, the MS/MS sequencing spectra show the presence of thiolated $U / \Psi$ (Supplemental Fig. S9A) and, only in tRNA-Val, the presence of a methylthio-

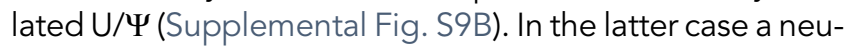
tral loss of 142 was observed, which corresponds to a modified $U$ with a methyl group and a sulfur atom, a situation that was not observed in the case of $m^{5} s^{2} U 54$-containing tRNAs of $P$. furiosus. The total absence of $m^{5} s^{2} U$ is also evident in the chromatogram profile of nucleoside digests from $S$. acidocaldarius, in comparison to $P$. furiosus (Supplemental Fig. S2). Altogether, these facts strongly suggest the presence of a methylthiolated derivative like $\mathrm{s}^{4} \mathrm{~m}^{1} \Psi$ as in I. hospitalis (Rose et al. 2020). This situation is however perplexing. Indeed, examination of the $S$. acidocaldarius genome reveals the lack of genes coding for both Pus10 (catalyzing formation of $\Psi 55$ and $\Psi 54$ ) and TrmY (catalyzing $\mathrm{m}^{1} \Psi$ ), while genes coding for TtuA and TtuB responsible for thiolation of $U / \Psi$ (into $s^{2} U$ or $s^{4} \Psi$ ) are present (Supplemental Table S2). It might be that in S. acidocaldarius a new type of $\mathrm{s}^{2} \mathrm{U} 54 / \mathrm{or} \mathrm{s}^{4} \Psi 54$-methylating enzyme exists. Therefore, we prefer to indicate that position as $\mathrm{s}^{\times} \mathrm{m}^{\times} \mathrm{U} / \Psi 54$.
In all three archaea analyzed, A58 is methylated at position $N 1$ ( $\left.m^{1} A 58\right)$, adding a positive charge on the base while still allowing for the formation of the usual trans Watson-Crick/Hoogsteen 54-58 pair (Supplemental Fig. S11B). In sum, thiolation of $m^{5} \mathrm{U}, \mathrm{m}^{1} \Psi$ and $\mathrm{U} / \mathrm{Um}$ at position 54 of tRNA appears as a hallmark of (hyper)thermophilic archaea. In thermophilic bacteria, such as Thermus thermophilus, the thiolation process was demonstrated to be thermo-inducible, as the level of 2-thiolation of $\mathrm{m}^{5} \mathrm{U} 54$ increases with the cultivation temperature (Shigi et al. 2006). The van der Waals radius of the sulfur atom is $0.3 \AA$ larger than that of the oxygen atom and its presence may fill the cavity present around that position in the overall compact T-loop, thereby excluding solvent molecules and promoting stacking.

Residue 56 is a conserved C, usually 2'-O-methylated on its ribose in almost all archaeal tRNAs analyzed so far (Clouet-d'Orval et al. 2005; Renalier et al. 2005). The ribose of $\mathrm{C} 56$ is highly accessible in the turn of the TYCloop and methylation allows protection against hydrolysis, especially at high temperatures. Cm56 forms a WatsonCrick pair with the conserved G19 of the D-loop (G19C56) and therefore cross-bridges the two parts of the tRNA core. Residue 57 is either $G$ or A where A57 is often doubly modified first into $\mathrm{m}^{1} \mathrm{~A}$, positively charged, and then into $\mathrm{m}^{1}$ I neutral (Grosjean et al. 1995). Residue 57 intercalates between the invariant $\mathrm{G} 18$ and the conserved G19-C56 pair. With G57, there is an $\mathrm{H}$-bond between $\mathrm{N} 2$ (G57) or N1(G57) and one anionic oxygen atom of the phosphodiester bond between 18 and 19 and with $\mathrm{m}^{1} 157$ the methyl group will be on the solvent exposed surface of the T-loop. It is noteworthy that nucleotide 17 is probably 2'-O-methylated on the ribose in S. acidocaldarius and $P$. furiosus, and 2-thiolated in $P$. furiosus and $M$. maripaludis (Fig. 3). The 2'-O-methyl group of $\mathrm{Cm} 56$ could protect the bent backbone from cleavage. Both $\mathrm{Cm} 56$ and $\mathrm{m}^{1} 157$ are unique and frequent in archaeal tRNAs (Table 1), while $m^{1} A 58$ is also present in many bacterial and eukaryotic tRNAs (Jühling et al. 2009).

\section{Modifications at position 34 (Table 2)}

The majority of the modifications observed at position 34 are the same as those identified in several tRNAs, mostly from Bacteria, such as $c m n m^{5} s^{2} U, m^{5} m^{5} U, c n m^{5} U$, $m c h m^{5} \mathrm{U}, \mathrm{Cm}, \mathrm{Um}, \mathrm{ac}^{4} \mathrm{C}$, except that, in the present thermophilic archaeal tRNAs, some of them are doubly modified with an extra $2^{\prime}-O$-methylribose, $\mathrm{mchm}^{5} \mathrm{Um}, \mathrm{ac}^{4} \mathrm{Cm}$, $s^{2}$ Um (Grosjean et al. 2008a,b, 2010; Jühling et al. 2009). In tRNA-Met' of M. maripaludis and P. furiosus (recognizable by the invariant last three $G=C$ pairs of the $A C$ stem [Kuchino et al. 1982]) and tRNA-Trp of $S$. acidocaldarius, there is a modified $\mathrm{Cm} 34$ (Table 2). The methyl group in that position occupies a tight space in the decoding site locking C34 for pairing only with G3 (Met codon AUG or 
Wolff et al.

TABLE 2. List of the archaeal tRNAs for which we could fully characterize the tRNA anticodon regions

\begin{tabular}{|c|c|c|}
\hline Amino acid & Anticodon & AC-loop \\
\hline Methanococcus maripaludis & & $32-38$ \\
\hline Asn & GUU & CUGUU $\left[h n^{6} \mathrm{~A}\right] \mathrm{A}$ \\
\hline Asp & GUC & CUGUC $\left[f^{6} \mathrm{~A}\right] \mathrm{C}$ \\
\hline Glu & UUC & $\mathrm{CU}\left[\overline{\mathrm{mnm}}^{5} \mathrm{U}\right] \cup C\left[\mathrm{~m}^{1} \mathrm{G}\right] \mathrm{A}$ \\
\hline Gly & UUC & $\mathrm{CU}\left[\overline{\mathrm{cnm} \mathrm{m}^{5}} \overline{\mathrm{C} C \mathrm{CAA}}\right.$ \\
\hline Ile & GAU & CUGAU[hn $\left.{ }^{6} A\right] A$ \\
\hline Ile & CAU & $\mathrm{CU} \overline{[\mathrm{C}+] \mathrm{A} U}\left[\mathrm{hn}{ }^{6} \mathrm{~A}\right] \mathrm{A}$ \\
\hline Lni & CAU & CUCAUAA \\
\hline Leu & UAG & $C\left[s^{2} U\right][x U] A G A A$ \\
\hline Lys & UUU & 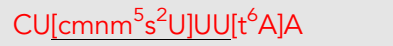 \\
\hline Met & CAU & 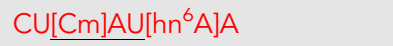 \\
\hline Phe & GAA & {$[\mathrm{Cm}] \cup \mathrm{GAA}[\mathrm{imG}-14] \mathrm{A}$} \\
\hline Tyr & GUA & {$[\mathrm{Cm}] \cup \mathrm{G} \cup A[x G] A$} \\
\hline Pyrococcus furiosus & & $32-38$ \\
\hline Ala & GGC & UUGGCAA \\
\hline Ala & UGC & $\mathrm{CU}\left[\mathrm{cnm}^{5} \mathrm{U}\right] \mathrm{GCAA}$ \\
\hline Arg & $\mathrm{CCU}$ & $\left.\left[\mathrm{s}^{2} \mathrm{C}\right] \cup \mathrm{CCU}\left[\mathrm{t}^{6} \mathrm{~A}\right]\right) \mathrm{A}$ \\
\hline Arg & UCU & $\mathrm{CU}\left[\mathrm{cnm} \overline{m^{5} U}\right] \mathrm{CUAA}$ \\
\hline Gln & UUG & $\mathrm{CU}\left[\overline{\left.\mathrm{cnm} \mathrm{m}^{5} \mathrm{U}\right] \mathrm{UGGA}}\right.$ \\
\hline Gln & CUG & $\mathrm{CU}\left[\mathrm{ac}^{4} \mathrm{Cm}\right] \cup \mathrm{UGA}$ \\
\hline Glu & CUC & $\mathrm{CUCUC}\left[\mathrm{m}^{1} \mathrm{G}\right] \mathrm{A}$ \\
\hline Gly & $\mathrm{CCC}$ & CUCCCAA \\
\hline Gly & GCC & CUGCCAA \\
\hline Gly & UCC & $\mathrm{CU}\left[\mathrm{cnm}^{5} \mathrm{U}\right] \mathrm{CC}\left[\mathrm{m}^{1} \mathrm{G}\right] \mathrm{A}$ \\
\hline Ile & GAU & CUGAU[hn $\left.{ }^{6} \mathrm{~A}\right] \mathrm{A}$ \\
\hline Lni & CAU & CUCAUAA \\
\hline Leu & CAG & UUCAGGG \\
\hline Leu & UAG & $U U\left[\mathrm{cnm}^{5} U\right] A G G G$ \\
\hline Lys & CUU & $\mathrm{CUCUU}\left[\mathrm{ms}^{2} \mathrm{t}^{6} \mathrm{~A}\right] \mathrm{A}$ \\
\hline Met & CAU & $\mathrm{CU}[\mathrm{Cm}] \mathrm{A} U\left[\mathrm{hn}{ }^{6} \mathrm{~A}\right] \mathrm{A}$ \\
\hline Phe & GAA & CUGAA[mimG]A/[Am] \\
\hline Pro & UGG & $U U\left[\mathrm{cnm}^{5} U\right] \mathrm{GG}\left[\mathrm{m}^{1} \mathrm{G}\right] \mathrm{GA}$ \\
\hline Thr & GGU & UUGGU[t $\left.\mathrm{t}^{6} \mathrm{~A}\right] /\left[\mathrm{hn}{ }^{6} \mathrm{~A}\right] \mathrm{A}$ \\
\hline Thr & UGU & $\mathrm{CU}\left[\mathrm{cnm}^{5} \mathrm{U}\right] \mathrm{GU}\left[\mathrm{hn}{ }^{6} \mathrm{~A}\right] \mathrm{A}$ \\
\hline Ser & GCU & CUGCU $\left[\mathrm{t}^{6} \mathrm{~A}\right] \mathrm{A}$ \\
\hline Val & GAC & CUGACAA \\
\hline Sulfolobus acidocaldarius & & $32-38$ \\
\hline Ala & UGC & {$[\mathrm{Cm}] \cup[\mathrm{Um}] \mathrm{GCAA}$} \\
\hline Asp & GUC & CUGUC $\left[m^{1} \mathrm{G}\right] /[\mathrm{imG} 2] /[\mathrm{mimG}] \mathrm{A}$ \\
\hline Gln & UUG & $\mathrm{CU} \overline{\mathrm{Um}]} /\left[\mathrm{s}^{2} \mathrm{Um}\right] \cup \mathrm{U}\left[\mathrm{m}^{1} \mathrm{G}\right] \mathrm{C}$ \\
\hline Glu & CUC & {$[\mathrm{Cm}] \cup C \cup C A A$} \\
\hline Gly & GCC & CUGCCAC \\
\hline Leu & CAG & {$[\mathrm{Cm}] \mathrm{U}[\mathrm{Cm}] \mathrm{AG}\left[\mathrm{m}^{1} \mathrm{G}\right] \mathrm{C}$} \\
\hline Leu & UAG & {$[\mathrm{Cm}] \cup\left[\mathrm{s}^{2} \cup \mathrm{m}\right] \mathrm{A} G\left[\mathrm{~m}^{1} \mathrm{G}\right] \mathrm{C}$} \\
\hline Lni & CAU & {$[\mathrm{Cm}] \cup \mathrm{CAUAA}$} \\
\hline Trp & CCA & {$[\mathrm{Cm}] \cup[\mathrm{Cm}] \mathrm{CA}[\mathrm{mimG}] \mathrm{A}$} \\
\hline Phe & GAA & CUGAA[mimG]A \\
\hline Tyr & GUA & CUGUA[mimG]A \\
\hline
\end{tabular}


TABLE 2. Continued

\begin{tabular}{lcc}
\hline Amino acid & Anticodon & AC-loop \\
\hline Val & GAC & {$[\mathrm{Cm}] \cup G A C\left[\mathrm{~m}^{1} \mathrm{G}\right] \mathrm{C}$} \\
Ser & UGA & CU $\left.\left.\underline{m} \mathrm{mchm}^{5} \mathrm{~mm}_{\mathrm{m}}\right] \mathrm{mimG}\right] \mathrm{mi}$ \\
\hline
\end{tabular}

This list is not as complete as those in the other figures or tables. Red nucleotides indicate fragments obtained by RNase T1 and/or RNase A digestion, while black nucleotides represent regions that could not be analyzed. Nucleotides in gray are modified nucleotides with a mass corresponding to several chemistries for modifications. Positions 34,35 , and 36 are underlined.

Trp codon UGG) and preventing mispairing of the C34 residue with A3 (lle codon AUA or stop codon UGA). The Cm34 modified nucleotide found in tRNA-Trp in S. acidocaldarius was previously observed in $\mathrm{H}$. volcanii (Gupta 1984) and in T. kodakarensis (Hirata et al. 2019). In tRNAlle, the anticodon CAU has to read exclusively the lle codon AUA and the C34-tRNA is modified into agmatidine $\left(C^{+}\right)$(lkeuchi et al. 2010; Mandal et al. 2010). The corresponding mass spectrum for tRNA-lle from $M$. maripaludis is shown on Supplemental Figure S8. In tRNA-G $\ln (C U G)$ of $P$. furiosus, the modified residue $\mathrm{ac}^{4} \mathrm{Cm} 34$, the same as in the homolog tRNA-Gln of H. volcanii, was found (Gupta 1984). NMR studies have shown that $\mathrm{ac}^{4} \mathrm{Cm}$ is exceptionally rigid in conformation owing to the additive nature of the acetylation and methylation modifications which stabilize the $3^{\prime}$-endo sugar conformation (Kawai et al. 1992). The same remark probably applies to Um34 and s² Um34 that occur in tRNA-GIn(UUG) and tRNA-Leu(UAG) of S. acidocaldarius. Interestingly, $\mathrm{ac}^{4} \mathrm{C}$ residues were also found in the acceptor stems of $P$. furiosus and $S$. acidocaldarius, as well as in the AC-stem of S. acidocaldarius (see above and Table 1). Modification of U34 is necessary for decoding G3 ending codons. The modification in U34 (U34*) changes the chemical structure of the U34 so that a pair U34*-G3, with the $U$ displaced into the minor groove, and not into the major groove, can be stabilized (Rozov et al. 2016; Westhof et al. 2019). Several U34-containing tRNAs were observed modified either at position C5 and/or at position C2. The case of xU34 in tRNA-Leu of M. maripaludis is explained below.

\section{Wyosine and modifications at position 37}

Residue 37 is commonly a purine, often (hyper)modified, that stacks on the first 1-36 bp formed between the codon and the anticodon during translation on the ribosome. Residue 37 should not be 2'-O-methylated because it forms an H-bond with N6(A1913) of helix H69 from the large subunit in the A state in known crystal structures of ribosomes (Supplemental Fig. S12D; Selmer et al. 2006). The type of modification at base 37 usually correlates with the rest of the so-called extended anticodon stemloop, especially with the adjacent nucleotide 36 of the anticodon (Yarus 1982; Grosjean and Westhof 2016). In E. coli, for example, $\mathrm{m}^{1} \mathrm{G}$ exclusively occurs in tRNAs rec- ognizing codons CCN (Pro), CGN (Arg), CUG (Leu), that is, in tRNAs decoding in the codon quadrant starting with C1 (Fig. 2; Supplemental Fig. S10). All the other tRNAs, belonging to the three remaining decoding quadrants, harbor either an unmodified $A 37$ or a modified $\mathrm{A} 37\left(\mathrm{~m}^{2} \mathrm{~A}, \mathrm{t}^{6} \mathrm{~A}, \mathrm{~m}^{6} \mathrm{t}^{6} \mathrm{~A}, \mathrm{~ms}^{2} \mathrm{i}^{6} \mathrm{~A}\right)$ with large modifications in the codon quadrants starting with U1 or A1 (Fig. 2; Supplemental Fig. S10). In the halophilic mesophilic $H$. volcanii, $\mathrm{m}^{1} \mathrm{G} 37$ occurs in tRNAs decoding codons starting with $\mathrm{C} 1$ (G-ending codons) and U1 (A-ending codons, with the exceptions of tRNA-Ser(CGA), tRNA-Ser(GGA) where A38 is found and tRNA-Glu(CUU) with $\mathrm{m}^{1} \mathrm{G}$; Gupta 1986). In all the other tRNAs of $H$. volcanii, $A 37$ or a modified A37 is used (Grosjean et al. 2008a).

In M. jannaschii, P. furiosus, M. maripaludis, and S. acidocaldarius, the landscape is striking. Indeed, the tRNAs for the codon quadrants starting with $\mathrm{C} 1$ and $\mathrm{U} 1$ contain $\mathrm{m}^{1} \mathrm{G}$ but also imG-14/imG2, a wyosine derivative of $\mathrm{m}^{1} \mathrm{G} 37$ that is reminiscent of the yW37 found exclusively in tRNA-Phe of Eukaryotes (de Crécy-Lagard et al. 2010). One finds indeed imG-14 or mimG at position 37 of tRNA-Phe(GAA) in $M$. maripaludis and $P$. furiosus with a wyosine-like $(x G)$ (as discussed below), in tRNA-Tyr(GUA) of $M$. maripaludis and mimG37 in tRNA-Arg(GCG) of P. furiosus (Fig. 2; Supplemental Fig. S10). In S. acidocaldarius, wyosine derivatives are present in tRNA-Asp(GUC), tRNA-Ser(UGA), tRNA-Phe(GAA), tRNA-Trp(CCA), and tRNA-Tyr(GUA). This surprising result was noted in the case of $M$. jannaschii (Yu et al. 2019) where besides tRNA-Phe, the tRNA-Arg (UCG), tRNA-Cys(GCA), tRNA-Leu(UAA), tRNA-Ser(GGA), and tRNA-Tyr(GUA) contain wyosine derivatives (Fig. 2). In T. kodakarensis (Hirata et al. 2019), mimG was found at position 37 of tRNA-Trp. Obviously, the presence of wyosine derivatives is more prevalent in Archaea than in Eukarya, especially in the U1-quadrant.

The tRNAs corresponding to the codon quadrants starting with $A 1$ still prefer large modifications on $A 37\left(t^{6} A\right.$, $m s^{2} t^{6} A, h n^{6} A$ ), while the $G 1$-quadrant prefers $A$ and in a few isolated cases also $\mathrm{m}^{1} \mathrm{G}$ (Fig. 2; Supplemental Fig. $\mathrm{S} 10)$. In the case of tRNA-Asp of $M$. maripaludis, a modified A37, which has the same nucleoside mass (295.1) than either di-methyl-A $\left(m_{2}^{6} A\right)$ or N6-formyl-A $\left(f^{6} A\right)$ was found. The latter $f^{6} A$ derivative is the most probable modification. The modified $\mathrm{f}^{6} \mathrm{~A}$ derivative has been identified in mammalian mRNAs (Fu et al. 2013). Interestingly, as discussed below, 

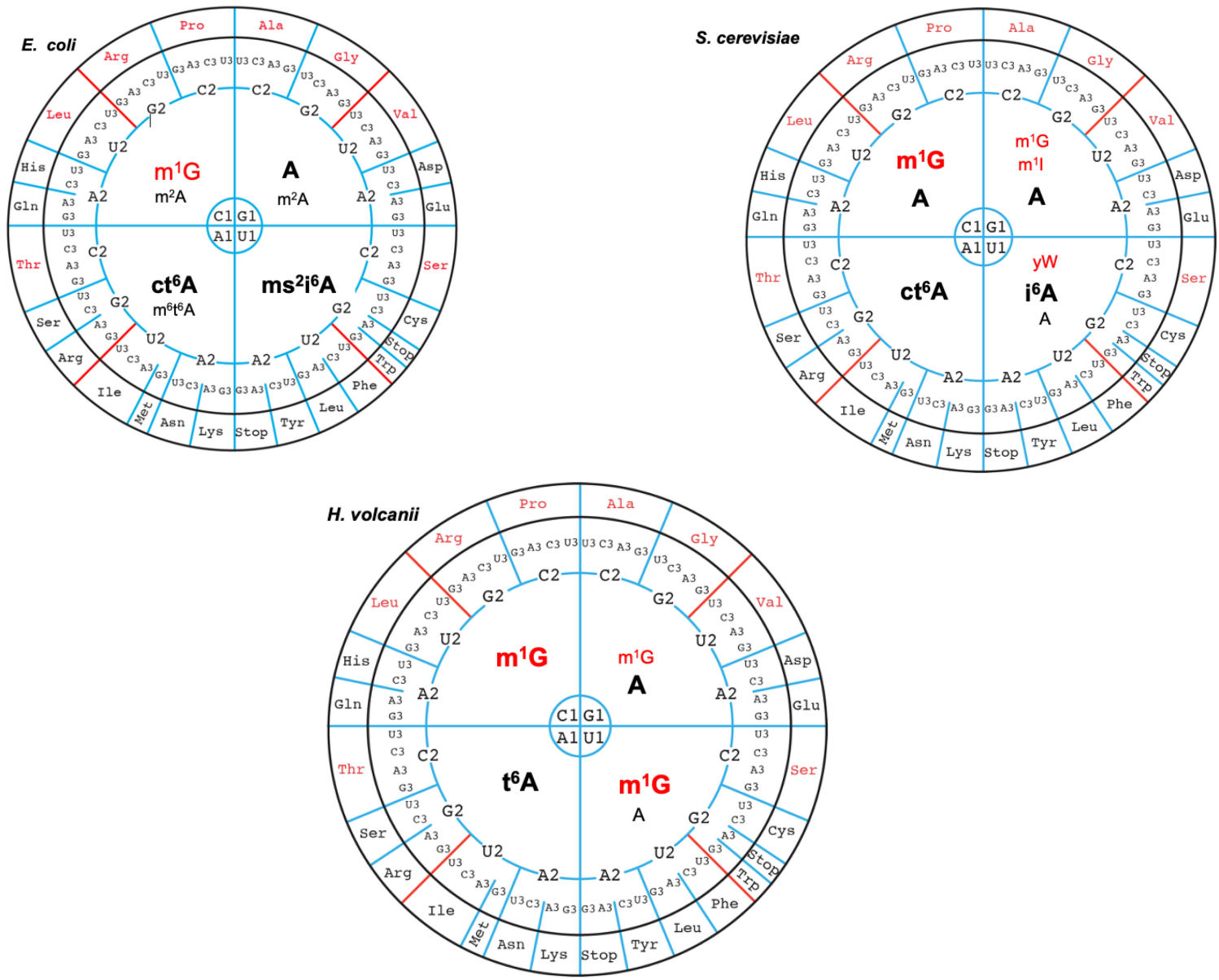

FIGURE 2. Patterns of distribution of modified nucleotides at position 37 in E. coli, S. cerevisiae and five archaeal species on the wheels of the genetic code (Grosjean and Westhof 2016). In that representation, GC-rich codons are at the top and AU-rich at the bottom of the wheel. The codon positions are numbered 1, 2, 3 so that G1A2C3 gives an Asp codon. The four quadrants are characterized by the first codon position. Data for E. coli and S. cerevisiae are from MODOMICS (Boccaletto et al. 2018). Data for H. volcanii are from Gupta (1984, 1986) and Grosjean et al. (2008a), data for M. jannaschii are from Yu et al. (2019). The wheels for E. coli, S. cerevisiae, and H. volcanii are adapted from Grosjean and Westhof (2016). In each quadrant, the observed modified nucleotides at position 37 are shown (red for $G$ derivatives and black for A derivatives; the very unusual U37 of tRNA-Ala(GGC) of $M$. jannaschii is also shown in black). The modifications observed frequently have a large font and are bold, while those observed only once or in a single tRNA species have a smaller font and are not bold.

in M. maripaludis, a mass corresponding to $a c^{6} \mathrm{~A}$, a modified nucleotide in the same biochemical pathway as $f^{6} \mathrm{~A}$, was observed for residue 7 of the acceptor stem. The homologous tRNA in $M$. jannaschii harbors an unmodified $A$. There is also one report of the presence of $\mathrm{m}_{2}^{6} \mathrm{~A}$ in Mycobacterium bovis, but without identification of either tRNA species or tRNA position (Chan et al. 2011). Also, in E. coli, tRNA-Val(UAC) contains m $^{6}$ A37 (Golovina et al. 2009).

Thus, as a rule, in Archaea, tRNAs decoding the codon quadrant starting with $\mathrm{C} 1$ and $\mathrm{U} 1$ harbor either unmodified A37 or mostly modified G37. The G1-quadrant has a preference for unmodified $A$ or slightly modified $A$ with some occurrences of modified G37. While tRNAs decoding the codon quadrant starting with $\mathrm{A} 1$ seem to harbor mostly hypermodified A37. In short, the stacking power of a G37 derivative (modified or not) on the first codon-anticodon base pair (Y1-R36) is obviously preferred for efficient decoding on the ribosome, while for R1-Y36 another type of stacked hypermodified A37 is favored. In addition to residue 37, other elements of the extended anticodon stem-loop, including generally simpler chemical modifications on the base and/or the ribose also contribute to the global efficiency and accuracy of the translation process, whatever the temperature at which the archaeon is growing. These rules are more restrictive than those observed in other organisms like E. coli, S. cerevisiae or $\mathrm{H}$. volcanii (Fig. 2; see Grosjean and Westhof 2016).

\section{Tentative identification of three novel modified nucleosides}

The sequence analysis of each tRNA allowed the detection of three possibly novel chemical modifications (designated $x G$ and $x U$ ). The first one was found at position $G 37$ of 

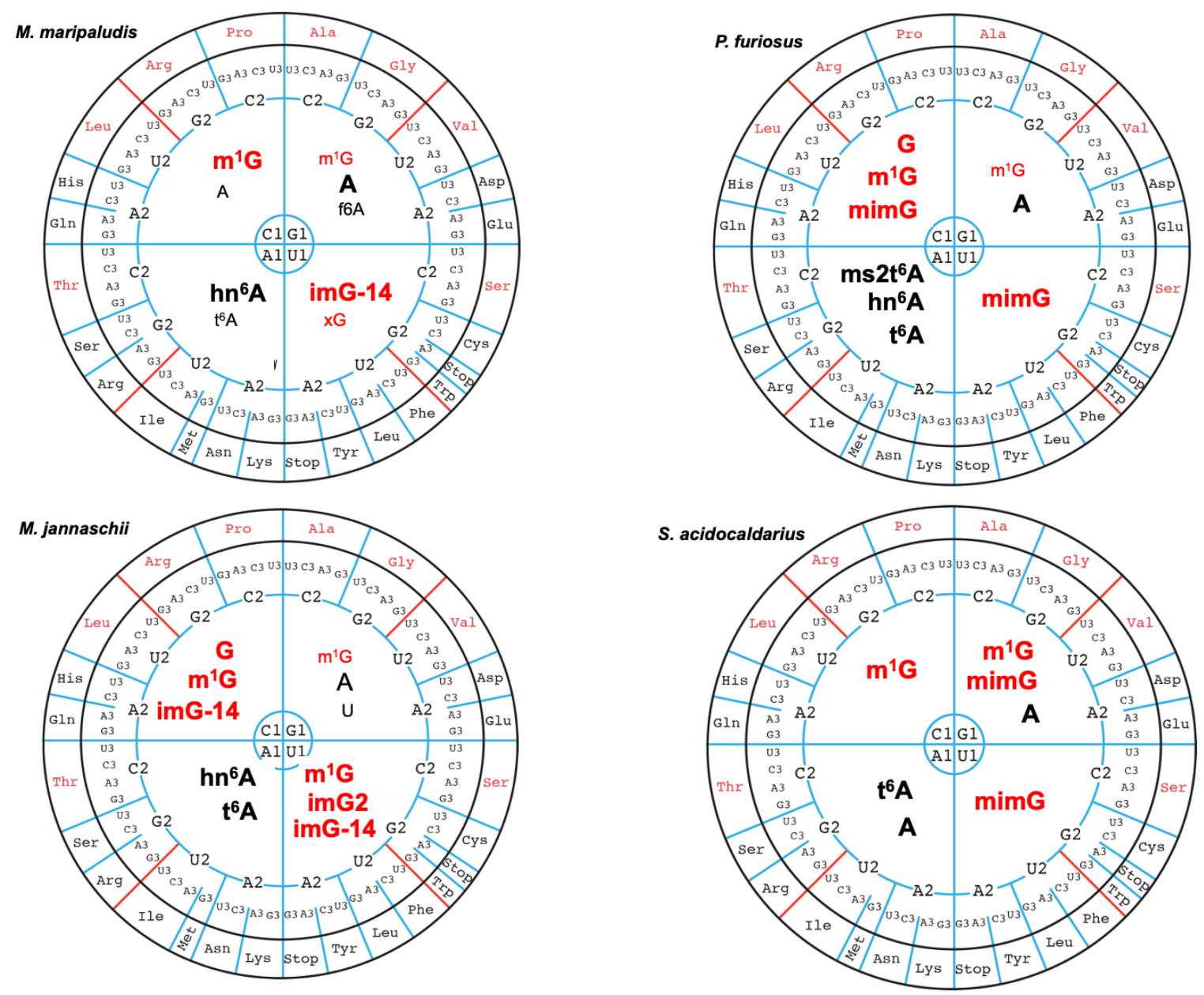

FIGURE 2. Continued.

tRNA-Tyr(GUA) of M. maripaludis (Supplemental Fig. S5) with a nucleoside mass of $392 \mathrm{Da}$, much higher than for the expected $\mathrm{m}^{1} \mathrm{G} 37$. In the homolog tRNA-Tyr of M. jannaschii, G37 is unexpectedly imG-14 of the wyosine metabolism (Yu et al. 2019). If this is also the case for M. maripaludis tRNA-Tyr, on the basis of previous work, one would therefore expect to find either imG, yW-86 or yW-72 (see G37 pathway \#5 in Fig. 4 of de Crécy-Lagard et al. 2010). Taking into account that CID fragmentation of $x G 37$ occurs between guanine and the modification, the MS/MS spectrum shows the complete mass of guanosine (345 Da) and a neutral loss of $109 \mathrm{Da}$ representing the mass of the adduct (Supplemental Fig. S5). The nucleoside mass of $x G(392 \mathrm{Da}$ ) could therefore correspond to $\mathrm{yW}-72$ (436.17 Da) with the loss (natural or accidental) of the carboxyl group (44.17 Da).

The second novel modification is $x U$ at position 34 of tRNA-Leu(xUAG) of $M$. maripaludis with a nucleoside mass of $269 \mathrm{Da}$. Again, in several tRNAs of M. jannaschii (Yu et al. 2019), either 5-cyanomethyl-U ( $\left.\mathrm{cnm}^{5} U\right)$ or 2-thiolated-5-cyanomethyl-U ( $\left.\mathrm{cnm}^{5} \mathrm{~s}^{2} \mathrm{U}\right)$ have been found, as in other archaeal tRNAs (Mandal et al. 2014). We propose that $\mathrm{xU} 34$ in $M$. maripaludis is the simpler 5-cyano-U $\left(\mathrm{cn}^{5} \mathrm{U}\right)$, with the cyano group directly linked to the $\mathrm{C} 5$ atom of uracil. Such a derivative is known from organic chemistry (Mao et al. 2018) but was never identified in tRNA so far.

A third unidentified modification, with a nucleoside mass of $338 \mathrm{Da}$, was found at position U47 of two tRNAs of $S$. acidocaldarius, tRNA-Val(GAC) (Supplemental Fig. S7A) and tRNA-Gly(GCC) (Supplemental Fig. S7B), two tRNAs of $S$. acidocaldarius, tRNA-Met elongator(CAU) (Supplemental Fig. S7C) and tRNA-Thr(UGU) of $P$. furiosus. In Bacteria and Eukarya, 3-(3-amino-3-carboxypropyl)-uridine $\left(\mathrm{acp}^{3} \mathrm{U}\right.$, nucleoside mass $\left.345.1 \mathrm{Da}\right)$ is widely conserved in the D- and variable loops (Takakura et al. 2019). It is likely that in hyperthermophilic archaea U47 is modified differently.

\section{DISCUSSION}

All the tRNA modifications identified in this work are compiled in several figures and tables. Figure 1 and 


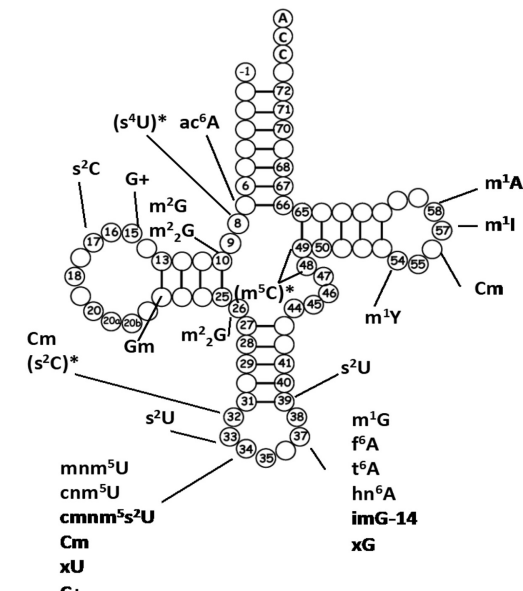

M. maripaludis

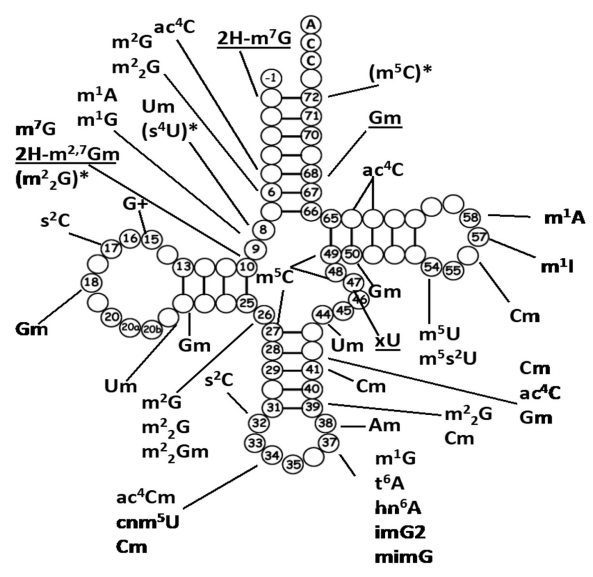

P. furiosus

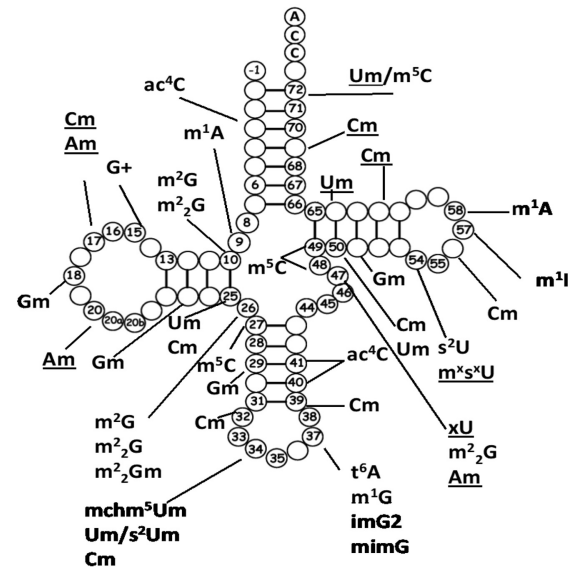

S. acidocaldarius

FIGURE 3. Nucleoside modification patterns in archaeal tRNAs determined by experimental MS/MS sequencing. The different modifications observed are reported on a typical cloverleaf two-dimensional structure. Underlined nucleotides are modified nucleotides with a mass corresponding to several possible chemistries for modifications, most of them corresponding to simple monomethylation products (see legend to Table 1). A "/" between two notations means a mixture of modifications. An " $x$ " before a nucleotide, for example, $x G$, or after a modification symbol, for example, $\mathrm{m}^{\mathrm{x}}$, means that the modification has not been formally identified (see text). Modified nucleotides indicated in brackets followed by an asterisk correspond to modifications deduced from the convergence of information from both the analysis of total tRNA and the presence of the gene coding for the corresponding modification enzyme in the genome of the particular archaeon. The modifications, uncertain or not completely identified, are underlined. Pseudouridines are not represented, except in the case of N1-methylpseudouridine ( $\left.\mathrm{m}^{1} \mathrm{Y}\right)$ because of the methyl group.

Supplemental Figure $\mathrm{S} 10$ align the intron-less tRNA sequences as deduced from the genomes on which the modified nucleotides are indicated; Figure 3 summarizes the data in cloverleaf representations; Supplemental Figure S3 displays the relative amounts of modified nucleosides identified in bulk tRNAs; Supplemental Tables S2 and S3 list the oligonucleotide fragments obtained after RNase digests. Supplemental Table S2 lists all the archaeal tRNA modification enzymes (and their corresponding coding genes) that have been experimentally validated so far in independent works or deduced from their close similarities with genuine modification enzymes in each of the Methanococcales, Pyrococcales and Sulfolobales groups of Archaea. Altogether, 79 naturally occurring fully matured isoacceptor tRNAs coding for 20 amino acids have been analyzed out of a theoretical total set of 116 species. Thus, the possibility still exists that a few modifications that are specific to the missing tRNAs (especially in the anticodon loop including the wobble position 34) still escaped our analysis.

Nevertheless, the major general conclusions that came out from this comparative analysis of modified nucleotide patterns in three very different archaeal species are the following: (i) the least diversified chemical modification pattern is observed in the mesophilic M. maripaludis; (ii) a larger diversity of modifications is found in the two hyperthermophiles; (iii) the largest amount of 2'-hydroxyl ribose methylations occurs in the acidophilic hyperthermophile $S$. acidocaldarius, most of them appear being catalyzed by
Fibrillarin-C/D box sRNP guide machinery; (iv) depending on the tRNA species, nucleotides at positions 32, 38, and 39 of the extended anticodon loop are frequently but diversely modified; $(v)$ beyond those found at positions 34 and 37 in the anticodon loop, a few characteristic modifications are found in the body of most if not all isoacceptor species of the three archaea $\left(\mathrm{G}^{+} 15\right.$ in the D-loop, $\mathrm{m}^{2} \mathrm{G}$ / $\mathrm{m}^{2}{ }_{2} \mathrm{G}$ at positions 10 and 26 at the beginning and the end of the D-arm, $\mathrm{m}^{5} \mathrm{C}$ at positions $48 / 49$ of the variable loop, $\mathrm{Cm} 56, \mathrm{~m}^{1} \mathrm{I} 57$ and $\mathrm{m}^{1} \mathrm{~A} 58$ in the TYC-loop), some of them are hallmarks of archaeal tRNAs; (vi) except for $\mathrm{ac}^{4} \mathrm{C}$ at the wobble position 34, this modified residue is present in the amino-acceptor and anticodon stems of only thermophilic archaeal tRNAs; (vii) at variance with the situation in bacterial and eukaryal tRNAs, $m^{2} \mathrm{G} / \mathrm{m}^{2}{ }_{2} \mathrm{G}$ are found at positions other than 10 and 26; (viii) remarkably, the chemical adducts on the conserved U54 of the T-loop depends on archaeon analyzed $\left(m^{1} \Psi, m^{5} \mathrm{U} /\right.$ $m^{5} s^{2} U$, or $s^{4} m^{1} \Psi$ ); (ix) the suggested presence of $m^{7} G$ modifications at the nucleotides 1 and 10 in $P$. furiosus would also be remarkable.

All these observations complete and reinforce similar conclusions made by others about the importance of certain post-transcriptional modifications for correct tRNA folding and on final cellular stability of the already G/C-rich tRNAs in thermophiles (Edmonds et al. 1991; Kowalak et al. 1994; McCloskey et al. 2001; Noon et al. 2003; for reviews, see Machnicka et al. 2014; Lorenz et al. 2017; Hori et al. 2018). As a rule, methylations 
promote precise $\mathrm{H}$-bonded pairs (e.g., $\mathrm{m}^{1} \mathrm{~A}$ favors

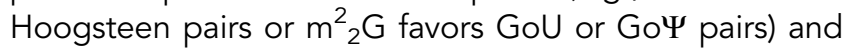
electrostatic charges introduced by the chemical adducts are localized in shielded pockets of the tRNA fold $\left(\mathrm{m}^{1} \mathrm{~A}\right.$, $\mathrm{m}^{7} \mathrm{G}$, archaeosine $\mathrm{G}^{+}$). Modifications in the tRNA core, although not close in sequence, tend to form clusters of modifications filling empty space on the surface of the compact tRNA core. In addition, methylations on the base and/or the ribose affect the hydration shells in complex ways (Auffinger and Westhof 2001). Thiolation of $U$ or $\mathrm{C}$, acetylation of $\mathrm{C}$, and isomerization of $\mathrm{U}$ to $\Psi$, can stabilize the $3^{\prime}$-endo sugar conformation, fill in space and enhance stacking power or base-pairing (Kawai et al. 1992; Davis 1995; Larsen et al. 2015; Sas-Chen et al. 2020). High-resolution crystallographic structures would be necessary to apprehend the effects of such complex modification scaffolds.

\section{MATERIALS AND METHODS}

\section{Culture and tRNA isolation}

Total tRNA of M. maripaludis and $P$. furiosus were prepared as described in de Crécy-Lagard et al. (2010). Total tRNA of S. acidocaldarius was obtained from a $12 \mathrm{~L}$ culture using the procedure described in Buck et al. (1983).

\section{Individual tRNA purification by two-dimensional PAGE}

tRNA isoacceptors were isolated using two-dimensional gel electrophoresis as previously described (Antoine et al. 2019; Antoine and Wolff 2020). Briefly, the total tRNA of each organism was separated in a first dimension gel under denaturing conditions using $12.5 \%$ polyacrylamide gel and $8 \mathrm{M}$ urea, followed by a second dimension under semi-denaturing conditions using $20 \%$ polyacrylamide gel and $4 \mathrm{M}$ urea at room temperature (Supplemental Fig. S1). Gel are staining with an ethidium bromide solution (10 $\mu \mathrm{g} . \mathrm{l}-1)$ for $10 \mathrm{~min}$. Spots containing tRNAs are visualized and excised under UV light (302 nm).

\section{In-gel RNase digestion}

Gel spots containing tRNAs were dried and rehydrated by $20 \mu \mathrm{L}$ of $0.1 \mathrm{U} / \mu \mathrm{L}$ of RNase T1 (ThermoFisher Scientific) or by $20 \mu \mathrm{L}$ of $0.01 \mathrm{U} / \mu \mathrm{L}$ of RNase A (Thermo Fisher Scientific) in $100 \mathrm{mM}$ ammonium acetate ( $\mathrm{pH}$ is not adjusted). For a few selected samples, spots were digested by RNase U2, by using $50 \mu \mathrm{L}$ of RNase U2 (homemade) at $0.3 \mathrm{ng} \cdot \mathrm{\mu L}^{-1}$ in $100 \mathrm{mM}$ ammonium acetate (pH is not adjusted). The spots were incubated $4 \mathrm{~h}$ at $50^{\circ} \mathrm{C}$. Using ZipTip C18 (Millipore) samples were desalted by several washes with $200 \mathrm{mM}$ ammonium acetate and eluted with $50 \%$ acetonitrile in milliQ water and dried under vacuum.

\section{NanoLC-MS/MS of RNA oligonucleotides}

Pellet containing RNase digestion products is resuspended in $3 \mu \mathrm{L}$ of milliQ water and separated on an Acquity peptide BEH C18 column (130 A, $1.7 \mu \mathrm{m}, 75 \mu \mathrm{m} \times 200 \mathrm{~mm}$ ) using a nanoAcquity system (Waters). The column was equilibrated in buffer $A$ containing $7.5 \mathrm{mM}$ TEAA (Triethylammonium acetate), $7.0 \mathrm{mM}$ TEA (Triethylammonium) and $200 \mathrm{mM}$ HFIP (Hexafluoroisopropanol) at a flow rate of $300 \mathrm{~nL} / \mathrm{min}$. Oligonucleotides were eluted using a gradient from $15 \%$ to $35 \%$ of buffer B (100\% methanol) for 2 min followed by elution with an increase of buffer B to $50 \%$ in $20 \mathrm{~min}$. MS and MS/MS analyses were performed using SYNAPT G2-S (quadrupole time-of-flight mass spectrometer) from Waters Corporation. All experiments were performed in negative mode with a capillary voltage set at $2.6 \mathrm{kV}$ and a sample cone voltage set at $30 \mathrm{~V}$. Source was heated to $130^{\circ} \mathrm{C}$. The samples were analyzed over an $\mathrm{m} / \mathrm{z}$ range from 500 to 1500 for the full scan, followed by fast data direct acquisition scan (Fast DDA).

\section{Data analysis}

All CID were deconvoluted using MassLynx software from Waters and manually sequenced by following the $y$ and/or $c$ series ( $w$ ions were also useful when sequencing was difficult or in order to confirm the sequence). Experimental masses of parents and fragments were compared to the theoretical masses obtained by the Mongo Oligo Mass Calculator (https://mods.rna.albany.edu/ masspec/Mongo-Oligo; Cantara et al. 2011). tRNA identification was done by comparisons with the genomic sequences obtained from GtRNAdb (http://gtrnadb.ucsc.edu/; Chan and Lowe 2009, 2016). Data about nucleoside modification were obtained from Modomics (Boccaletto et al. 2018).

\section{Data analysis by MassSpec-Toolkit for RNAs}

The identification and characterization of modified tRNAs by LCMS/MS spectrum analysis is difficult and time-consuming. To help in this process, we implemented MassSpec-Toolkit for RNAs, a Python web application (http://labex-ibmc.u-strasbg.fr/ MassSpec-Toolkit/, accessible upon request) linked to a local MongoDB database that stores user-provided RNA genomic sequences and their theoretical digestion products obtained by specific ribonucleases. For each studied species, mature tRNA sequences retrieved from GtRNAdb (Chan and Lowe 2009, 2016) were submitted to the application and digested in silico with RNases T1, A and/or U2, in the "RNA Digestion" module. Genomic tRNA sequences longer than $100 \mathrm{nt}$ were discarded and for the remaining ones with a nonambiguous anticodon position, fragments with common U34 or G34 and/or A37 or G37 modifications were generated when appropriate. In addition, fragment variants containing up to five additional methylations were also computed for each digestion product. Experimental data such as parent ion masses or manually reconstructed subsequences could then be compared to the theoretical ones in the "RNA Search" module. Additional criteria, like the species of interest, the ribonuclease used, as well as the presence of expected methylations or modifications at specific positions, can be specified to reduce the search space in the database. Candidate tRNAs are given a score comprised between 0 and 1 depending on the number of matching masses or subsequences they present with the list provided by the user. Besides these two main modules, the application gathers a set of "Additional Tools" under a third module that includes some of the tools present in the Mongo 
Oligo Mass Calculator (Cantara et al. 2011) and "Total Mass Decipherer." The latter program can be very useful to identify modifications in case of incomplete MS/MS series, since it computes all combinations of a chosen set of (modified) nucleotides matching the mass of an RNA fragment obtained after cleavage by RNase T1.

\section{RNase cleavage}

LC MS/MS of digestion products allows the localization of methylation in the correct nucleotide but does not allow the localization on the ribose or on the base (Supplemental Table S1). To correctly assign the type of methylation, we used known modified tRNA sequences and the presence of modification enzymes in the species genome (Supplemental Table S2). To confirm the type of methylation, we also used RNase T1 and RNase A cleavage profiles. Indeed, a methyl group on the 2' ribose protects RNA against RNase cleavages. With the methyl group on the base, the interpretation of RNase cleavages is not straightforward. Our data show that in the case of RNase $T 1, \mathrm{~m}^{2} \mathrm{G}$ and $\mathrm{m}^{2}{ }_{2} \mathrm{G}$ can be cleaved (one example for each, $\mathrm{m}^{2} \mathrm{G} 10$ in $\mathrm{S}$. acidocaldarius tRNA-Trp and $m^{2}{ }_{2} G 39$ in P. furiosus tRNA-Ser[GGA]) but $m^{7} G$, $m^{1} G$ are never cleaved. With RNase $A, m^{5} C$ and $m^{1} Y$ are cleaved and $U m, m^{5} U$ and $m^{5} s^{2} U$ are not cleaved. It is interesting to note that, for tRNA-Cys and tRNA-Met of $P$. furiosus tRNAs, RNase A does not cleave $m^{5} U 54$. A previous work shows that $m^{5} U 54$ is always cleaved (Antoine and Wolff 2020). A possible explanation is the presence of a stretch of three to four Gs $5^{\prime}$ preceding the modified $\mathrm{m}^{5} \mathrm{U} 54$ that could prevent access and binding of RNase A.

\section{LC-MS/MS of nucleosides}

Total tRNA was desalted by ethanolic precipitation with $200 \mathrm{mM}$ ammonium acetate (Supplemental Figs. S2, S3). For nucleoside analysis, tRNAs are diluted to a concentration of $5 \mu \mathrm{g} / \mu \mathrm{L}$ in $\mathrm{H}_{2} \mathrm{O}$. Digestion was carried out in the following order: $14 \mu \mathrm{L}$ $\mathrm{H}_{2} \mathrm{O} ; 2 \mu \mathrm{L}$ buffer P1 $10 \times\left(2 \mathrm{mM} \mathrm{ZnCl} 2,250\right.$ mM NH${ }_{4} \mathrm{OAc}, \mathrm{pH}$ 5.0); $21 \mu \mathrm{L}$ of tRNA and $2 \mu \mathrm{L}$ of $\mathrm{P} 1(0.5 \mathrm{U} / \mu \mathrm{L})$. The mixture is incubated at $37^{\circ} \mathrm{C}$ for $2 \mathrm{~h}$ followed by addition of $2 \mu \mathrm{L}$ of snake venom phosphodiesterase $(0.1 \mathrm{U} / \mu \mathrm{L})$ for $4 \mathrm{~h}$ at $37^{\circ} \mathrm{C}$. After digestion, 20 $\mu \mathrm{L}$ of BAP $\left(1.5 \mathrm{U} / \mu \mathrm{L}\right.$ in $\left.100 \mathrm{mM} \mathrm{NH}_{4} \mathrm{OAc}\right)$ were added to the mixture. The latter was then incubated at $37^{\circ} \mathrm{C}$ for $2 \mathrm{~h}$, dried under vacuum SpeedVac and resuspended with $100 \mu$ l of methanol. Nucleosides were analyzed by liquid chromatography coupled to mass spectrometry using an Ultimate 3000 (Thermo) chromatography coupled to an EvoQ triple quadrupole (Bruker). Separation was performed on an Acquity UPLC HSST3 column $(1.8 \mu \mathrm{m}, 2.1 \times 100 \mathrm{~mm}$, Waters) equipped with an Acquity UPLC HSST3 precolumn ( $1.8 \mu \mathrm{m}, 2.1 \times 5 \mathrm{~mm}$, Waters). A gradient of solvent $A\left(\mathrm{H}_{2} \mathrm{O}, 0.1 \%\right.$ formic acid [Sigma Aldrich]) and solvent $B$ (methanol [Fisher Chemicals], 0.1\% formic acid [Sigma Aldrich]) was used as follows: $2 \%$ B during $2 \mathrm{~min}, 7 \% \mathrm{~B}$ at $4 \mathrm{~min}, 100 \% \mathrm{~B}$ at $12 \mathrm{~min}$, hold during $1.5 \mathrm{~min}$ and back to $2 \%$ of $B$ at $13.5 \mathrm{~min}$, hold during $1.5 \mathrm{~min}$ for a total run time of $15 \mathrm{~min}$. The column was operated at $35^{\circ} \mathrm{C}$ with a flow rate of $0.32 \mathrm{~mL} / \mathrm{min} ; 10 \mu \mathrm{L}$ of samples were injected for each run. The triple quadrupole was used in positive ion mode, the spray voltage was set at $3500 \mathrm{~V}$ and cone temperature at $350^{\circ} \mathrm{C}$. Nucleosides were identified using multiple reaction monitoring (MRM) with one to three transi- tions per nucleotide. The identifications were based on the retention time, $\mathrm{m} / \mathrm{z}$ of the parent ion and $\mathrm{m} / \mathrm{z}$ of the daughter ions in MS Data Review software (Bruker), with a signal-to-noise $(\mathrm{S} / \mathrm{N})$ ratio set at 10 and a search window of $\pm 0.2 \mathrm{~min}$.

\section{SUPPLEMENTAL MATERIAL}

Supplemental material is available for this article.

\section{ACKNOWLEDGMENTS}

We wish to thank the three reviewers for their constructive comments. E.W. wishes to thank G. and D. Crahay for their hospitality during the coronavirus lockdown. The project was supported by the French National Program Investissement d'Avenir (Labex NetRNA) administered by the Agence Nationale de la Recherche (ANR-10-LABX-0036_NETRNA) and ANR-15-CE110021-01 [to E.W.]) and by the EpiRNA funding from the Region Grand Est.

Received August 1, 2020; accepted September 9, 2020.

\section{REFERENCES}

Alfonzo JD, Blanc V, Estevez AM, Rubio MA, Simpson L. 1999. C to U editing of the anticodon of imported mitochondrial tRNATrp allows decoding of the UGA stop codon in Leishmania tarentolae. EMBO J 18: 7056-7062. doi:10.1093/emboj/18.24.7056

Antoine L, Wolff P. 2020. Mapping of posttranscriptional tRNA modification by two-dimensional gel electrophoresis mass spectrometry. Methods Mol Biol 2113: 101-110. doi:10.1007/978-1-07160278-2_8

Antoine L, Wolff P, Westhof E, Romby P, Marzi S. 2019. Mapping posttranscriptional modifications in Staphylococcus aureus tRNAs by nanoLC/MSMS. Biochimie 164: 60-69. doi:10.1016/j.biochi .2019 .07 .003

Auffinger $P$, Westhof E. 2001. Hydrophobic groups stabilize the hydration shell of 2'-O-methylated RNA duplexes. Angew Chem Int Ed Engl 40: 4648-4650. doi:10.1002/1521-3773(20011217)40 :24<4648::AID-ANIE4648>3.0.CO;2-U

Boccaletto P, Machnicka MA, Purta E, Piạtkowski P, Bagiński B, Wirecki TK, de Crécy-Lagard V, Ross R, Limbach PA, Kotter A, et al. 2018. MODOMICS: a database of RNA modification pathways. 2017 update. Nucleic Acids Res 46: D303-D307. doi:10 $.1093 / \mathrm{nar} / \mathrm{gkx} 1030$

Buck M, Connick M, Ames BN. 1983. Complete analysis of tRNAmodified nucleosides by high-performance liquid chromatography: the 29 modified nucleosides of Salmonella typhimurium and Escherichia coli. Anal Biochem 129: 1-13. doi:10.1016/ 0003-2697(83)90044-1

Cantara WA, Crain PF, Rozenski J, McCloskey JA, Harris KA, Zhang X, Vendeix FA, Fabris D, Agris PF. 2011. The RNA Modification Database, RNAMDB: 2011 update. Nucleic Acids Res 39: D195D201. doi:10.1093/nar/gkq1028

Cantara WA, Murphy F, Demirci H, Agris PF. 2013. Expanded use of sense codons is regulated by modified cytidines in tRNA. Proc Natl Acad Sci 110: 10964-10969. doi:10.1073/pnas.1222641110

Chan PP, Lowe TM. 2009. GtRNAdb: a database of transfer RNA genes detected in genomic sequence. Nucleic Acids Res 37: D93-D97. doi:10.1093/nar/gkn787

Chan PP, Lowe TM. 2016. GtRNAdb 2.0: an expanded database of transfer RNA genes identified in complete and draft genomes. Nucleic Acids Res 44: D184-D189. doi:10.1093/nar/gkv1309 
Chan CT, Chionh YH, Ho CH, Lim KS, Babu IR, Ang E, Wenwei L, Alonso S, Dedon PC. 2011. Identification of $N^{6}, N^{6}$-dimethyladenosine in transfer RNA from Mycobacterium bovis Bacille Calmette-Guérin. Molecules 16: 5168-5181. doi:10.3390/ molecules16065168

Chatterjee K, Blaby IK, Thiaville PC, Majumder M, Grosjean H, Yuan YA, Gupta R, de Crécy-Lagard V. 2012. The archaeal COG1901/DUF358 SPOUT-methyltransferase members, together with pseudouridine synthase Pus10, catalyze the formation of 1methylpseudouridine at position 54 of tRNA. RNA 18: 421-433. doi:10.1261/rna.030841.111

Clouet d'Orval B, Bortolin ML, Gaspin C, Bachellerie JP. 2001. Box C/ D RNA guides for the ribose methylation of archaeal tRNAs. The tRNATrp intron guides the formation of two ribose-methylated nucleosides in the mature tRNATrp. Nucleic Acids Res 29: 45184529. doi:10.1093/nar/29.22.4518

Clouet-d'Orval B, Gaspin C, Mougin A. 2005. Two different mechanisms for tRNA ribose methylation in Archaea: a short survey. Biochimie 87: 889-895. doi:10.1016/j.biochi.2005.02.004

Crain PF, Alfonzo JD, Rozenski J, Kapushoc ST, Mccloskey JA, Simpson L. 2002. Modification of the universally unmodified uridine-33 in a mitochondria-imported edited tRNA and the role of the anticodon arm structure on editing efficiency. RNA 8: 752776. doi:10.1017/S1355838202022045

Dalluge JJ, Hamamoto T, Horikoshi K, Morita RY, Stetter KO, McCloskey JA. 1997. Posttranscriptional modification of tRNA in psychrophilic bacteria. J Bacteriol 179: 1918-1923. doi:10.1128/ JB.179.6.1918-1923.1997

Davis DR. 1995. Stabilization of RNA stacking by pseudouridine. Nucleic Acids Res 23: 5020-5026. doi:10.1093/nar/23.24.5020

de Crécy-Lagard V, Brochier-Armanet C, Urbonavicius J, Fernandez B, Phillips G, Lyons B, Noma A, Alvarez S, Droogmans L, Armengaud J, et al. 2010. Biosynthesis of wyosine derivatives in tRNA: an ancient and highly diverse pathway in archaea. Mol Biol Evol 27: 2062-2077. doi:10.1093/molbev/msq096

Dennis PP, Omer A, Lowe T. 2001. A guided tour: small RNA function in Archaea. Mol Microbiol 40: 509-519. doi:10.1046/j.1365-2958 .2001.02381.x

Edmonds CG, Crain PF, Gupta R, Hashizume T, Hocart CH, Kowalak JA, Pomerantz SC, Stetter KO, McCloskey JA. 1991. Posttranscriptional modification of tRNA in thermophilic archaea (Archaebacteria). J Bacteriol 173: 3138-3148. doi:10.1128/JB .173.10.3138-3148.1991

Emery LR, Sharp PM. 2011. Impact of translational selection on codon usage bias in the archaeon Methanococcus maripaludis. Biol Lett 7: 131-135. doi:10.1098/rsbl.2010.0620

Forterre P. 2015. The universal tree of life: an update. Front Microbiol 6: 717. doi:10.3389/fmicb.2015.00717

Fu Y, Jia G, Pang X, Wang RN, Wang X, Li CJ, Smemo S, Dai Q, Bailey KA, Nobrega MA, et al. 2013. FTO-mediated formation of $\mathrm{N}^{6}$-hydroxymethyladenosine and $\mathrm{N}^{6}$-formyladenosine in mammalian RNA. Nat Commun 4: 1798. doi:10.1038/ncomms2822

Fukunaga R, Yokoyama S. 2007. Structural insights into the first step of RNA-dependent cysteine biosynthesis in archaea. Nat Struct Mol Biol 14: 272-279. doi:10.1038/nsmb1219

Gaspin C, Cavaillé J, Erauso G, Bachellerie JP. 2000. Archaeal homologs of eukaryotic methylation guide small nucleolar RNAs: lessons from the Pyrococcus genomes. J Mol Biol 297: 895-906. doi:10.1006/jmbi.2000.3593

Giegé R, Springer M. 2016. Aminoacyl-tRNA synthetases in the bacterial world. EcoSal Plus 7. doi:10.1128/ecosalplus.ESP-0002-2016

Golovina AY, Sergiev PV, Golovin AV, Serebryakova MV, Demina I, Govorun VM, Dontsova OA. 2009. The yfiC gene of E. coli encodes an adenine- $N^{6}$ methyltransferase that specifically modifies
A37 of tRNA1Val(cmo5UAC). RNA 15: 1134-1141. doi:10.1261/ rna.1494409

Grosjean H, Westhof E. 2016. An integrated, structure- and energybased view of the genetic code. Nucleic Acids Res 44: 80208040. doi:10.1093/nar/gkw608

Grosjean H, Constantinesco F, Foiret D, Benachenhou N. 1995. A novel enzymatic pathway leading to 1-methylinosine modification in Haloferax volcanii tRNA. Nucleic Acids Res 23: 4312-4319. doi:10.1093/nar/23.21.4312

Grosjean H, Gaspin C, Marck C, Decatur WA, de Crécy-Lagard V. 2008a. RNomics and Modomics in the halophilic archaea Haloferax volcanii: identification of RNA modification genes. BMC Genomics 9: 470-496. doi:10.1186/1471-2164-9-470

Grosjean H, Gupta R, Maxwell ES. 2008b. Modified nucleotides in Archaeal RNAs. In Archaea, new models for prokaryotic biology (ed. Blum P), pp. 171-196. Caister Academic Press, Norfolk, UK.

Grosjean H, de Crécy-Lagard V, Marck C. 2010. Deciphering synonymous codons in the three domains of life: co-evolution with specific tRNA modification enzymes. FEBS Lett 584: 252-264. doi:10 .1016/j.febslet.2009.11.052

Gupta R. 1984. Halobacterium volcanii tRNAs. Identification of 41 tRNAs covering all amino acids, and the sequences of 33 class I tRNAs. J Biol Chem 259: 9461-9471.

Gupta R. 1986. Transfer RNAs of Halobacterium volcanii: sequences of five leucine and three serine tRNAs. Syst Appl Microbiol 7: 102-105. doi:10.1016/S0723-2020(86)80131-X

Haag S, Warda AS, Kretschmer J, Günnigmann MA, Höbartner C, Bohnsack MT. 2015. NSUN6 is a human RNA methyltransferase that catalyzes formation of $\mathrm{m}^{5} \mathrm{C} 72$ in specific tRNAs. RNA 21: 1532-1543. doi:10.1261/rna.051524.115

Helm M. 2006. Post-transcriptional nucleotide modification and alternative folding of RNA. Nucleic Acids Res 34: 721-733. doi:10 $.1093 /$ nar/gkj471

Helm M, Alfonso JD. 2014. Posttranscriptional RNA modifications: playing metabolic games in a cell's chemical legoland. Chem Biol 21: 174-185. doi:10.1016/j.chembiol.2013.10.015

Hirata A, Suzuki T, Nagano T, Fujii D, Okamoto M, Sora M, Lowe TM, Kanai T, Atomi H, Suzuki T, et al. 2019. Distinct modified nucleosides in tRNATrp from the hyperthermophilic archaeon Thermococcus kodakarensis and requirement of tRNA m2G10/ m22G10 methyltransferase (Archaeal Trm11) for survival at high temperatures. J Bacteriol 201: e00448-19. doi:10.1128/JB .00448-19

Hori H, Kawamura T, Awai T, Ochi A, Yamagami R, Tomikawa C, Hirata A. 2018. Transfer RNA modification enzymes from thermophiles and their modified nucleosides in tRNA. Microorganisms 6: 110. doi:10.3390/microorganisms 6040110

Ikeuchi Y, Kimura S, Numata T, Nakamura D, Yokogawa T, Ogata T, Wada T, Suzuki T, Suzuki T. 2010. Agmatine-conjugated cytidine in a tRNA anticodon is essential for AUA decoding in archaea. Nat Chem Biol 6: 277-282. doi:10.1038/nchembio.323

Jühling F, Mörl M, Hartmann RK, Sprinzl M, Stadler PF, Pütz J. 2009. tRNAdb 2009: compilation of tRNA sequences and tRNA genes. Nucleic Acids Res 37: D159-D162. doi:10.1093/nar/gkn772

Karlsborn T, Tükenmez H, Mahmud AKMF, Xu F, Xu H, Byström AS. 2014. Elongator, a conserved complex required for wobble uridine modifications in eukaryotes. RNA Biol 11: 1519-1528. doi:10 $.4161 / 15476286.2014 .992276$

Kawai G, Yamamoto Y, Kamimura T, Masegi T, Sekine M, Hata T, limori T, Watanabe T, Miyazawa T, Yokoyama S. 1992. Conformational rigidity of specific pyrimidine residues in tRNA arises from posttranscriptional modifications that enhance steric interaction between the base and the 2'-hydroxyl group. Biochemistry 31: 1040-1046. doi:10.1021/bi00119a012 
Kempenaers M, Roovers M, Oudjama Y, Tkaczuk KL, Bujnicki JM, Droogmans L. 2010. New archaeal methyltransferases forming 1 methyladenosine or 1-methyladenosine and 1-methylguanosine at position 9 of tRNA. Nucleic Acids Res 38: 6533-6543. doi:10 $.1093 / \mathrm{nar} / \mathrm{gkq} 451$

Kowalak JA, Dalluge JJ, McCloskey JA, Stetter KO. 1994. The role of posttranscriptional modification in stabilization of transfer RNA from hyperthermophiles. Biochemistry 33: 7869-7876. doi:10 .1021/bi00191a014

Krishnamohan A, Samantha Dodbele S, Jackman JE. 2019. Insights into catalytic and tRNA recognition mechanism of the dual-specific tRNA methyltransferase from Thermococcus kodakarensis. Genes (Basel) 10: 100. doi:10.3390/genes10020100

Kuchino Y, Ihara M, Yabusaki Y, Nishimura S. 1982. Initiator tRNAs from archaebacteria show common unique sequence characteristics. Nature 298: 684-685. doi:10.1038/298684a0

Larsen AT, Fahrenbach AC, Sheng J, Pian J, Szostak JW. 2015 Thermodynamic insights into 2-thiouridine-enhanced RNA hybridization. Nucleic Acids Res 43: 7675-7687. doi:10.1093/nar/ gkv761

Lorenz C, Lünse CE, Mörl M. 2017. tRNA modifications: impact on structure and thermal adaptation. Biomolecules 7: 35. doi:10 .3390/biom7020035

Lowe TM, Eddy SR. 1997. tRNAscan-SE: a program for improved detection of transfer RNA genes in genomic sequence. Nucleic Acids Res 25: 955-964. doi:10.1093/nar/25.5.955

Machnicka MA, Olchowik A, Grosjean H, Bujnicki JM. 2014. Distribution and frequencies of post-transcriptional modifications in tRNAs. RNA Biol 11: 1619-1629. doi:10.4161/15476286.2014 .992273

Mandal D, Köhrer C, Su D, Russell SP, Krivos K, Castleberry CM, Blum P, Limbach PA, Söll D, RajBhandary UL. 2010. Agmatidine, a modified cytidine in the anticodon of archaeal tRNA ${ }^{\mathrm{lle}}$, base pairs with adenosine but not with guanosine. Proc Natl Acad Sci 107: 2872-2877. doi:10.1073/pnas.0914869107

Mandal D, Köhrer C, Su D, Babu IR, Chan CT, Liu Y, Söll D, Blum P, Kuwahara M, Dedon PC, et al. 2014. Identification and codon reading properties of 5-cyanomethyl uridine, a new modified nucleoside found in the anticodon wobble position of mutant haloarchaeal isoleucine tRNAs. RNA 20: 177-188. doi:10.1261/rna .042358 .113

Mao S, Ranganathan SV, Tsai HC, Haruehanroengra $P$, Shen $F$, Valsangkar VA, Han B, Hassan AEA, Chen A, Sheng J. 2018. Cyano modification on uridine decreases base-pairing stability and specificity through neighboring disruption in RNA duplex. Chembiochem 19: 2558-2565. doi:10.1002/cbic.201800399

Marck C, Grosjean H. 2002. tRNomics: analysis of tRNA genes from 50 genomes of Eukarya, Archaea, and Bacteria reveals anticodonsparing strategies and domain-specific features. RNA 8: 11891232. doi:10.1017/S1355838202022021

McCloskey JA, Graham DE, Zhou S, Crain PF, Ibba M, Konisky J, Söll D, Olsen GJ. 2001. Post-transcriptional modification in archaeal tRNAs: identities and phylogenetic relations of nucleotides from mesophilic and hyperthermophilic Methanococcales. Nucleic Acids Res 29: 4699-4706. doi:10.1093/nar/29.22.4699

Motorin Y, Helm M. 2010. tRNA stabilization by modified nucleotides. Biochemistry 49: 4934-4944. doi:10.1021/bi100408z

Motorin Y, Helm M. 2011. RNA nucleotide methylation. WIREs RNA 2: 611-631. doi:10.1002/wrna.79

Nakamura Y, Gojobori T, Ikemura T. 2000. Codon usage tabulated from the international DNA sequence databases: status for the year 2000. Nucleic Acids Res 28: 292. doi:10.1093/nar/28.1.292

Nayak KC. 2013. Comparative genome sequence analysis of Sulfolobus acidocaldarius and 9 other isolates of its genus for fac- tors influencing codon and amino acid usage. Gene 513: 163173. doi:10.1016/j.gene.2012.10.024

Noon KR, Guymon R, Crain PF, McCloskey JA, Thomm M, Lim J, Cavicchioli R. 2003. Influence of temperature on tRNA modification in archaea: Methanococcoides burtonii (optimum growth temperature [Topt], 23 degrees $C$ ) and Stetteria hydrogenophila (Topt, 95 degrees C). J. Bacteriol 185: 5483-5490. doi:10.1128/ JB.185.18.5483-5490.2003

Ohira T, Suzuki T. 2016. Precursors of tRNAs are stabilized by methylguanosine cap structures. Nat Chem Biol 12: 648-655. doi:10 .1038/nchembio.2117

Omer AD, Lowe TM, Russell AG, Ebhardt H, Eddy SR, Dennis PP. 2000. Homologs of small nucleolar RNAs in Archaea. Science 288: 517-522. doi:10.1126/science.288.5465.517

Pang $H$, Ihara $M$, Kuchino $Y$, Nishimura S, Gupta R, Woese CR, McCloskey JA. 1982. Structure of a modified nucleoside in archaebacterial tRNA which replaces ribosylthymine 1-methylpseudouridine. J Biol Chem 257: 3589-3592.

Plesiewicz E, Stepień E, Bolewska K, Wierzchowski KL. 1976. Stacking self-association of pyrimidine nucleosides and of cytosines: effects of methylation and thiolation. Nucleic Acids Res 3: 1295-1306. doi:10.1093/nar/3.5.1295

Pollo-Oliveira L, de Crécy-Lagard V. 2019. Can protein expression be regulated by modulation of tRNA modifications profiles? Biochemistry 58: 355-362. doi:10.1021/acs.biochem.8b01035

Renalier MH, Joseph N, Gaspin C, Thebault P, Mougin A. 2005. The Cm56 tRNA modification is catalyzed either by a specific 2'-Omethylase, or a C/D sRNP in Archaea. RNA 11: 1051-1063. doi:10.1261/rna.2110805

Rose S, Auxilien S, Havelund JF, Kirpekar F, Huber H, Grosjean H, Douthwaite S. 2020. The hyperthermophilic partners Nanoarchaeum and Ignicoccus stabilize their tRNA T-loops via different but structurally equivalent modifications. Nucleic Acids Res 48: 6906-6918. doi:10.1093/nar/gkaa411

Rozov A, Demeshkina N, Khusainov I, Westhof E, Yusupov M, Yusupova G. 2016. Novel base-pairing interactions at the tRNA wobble position crucial for accurate reading of the genetic code. Nat Commun 7: 10457. doi:10.1038/ncomms10457

Sas-Chen A, Thomas JM, Matzov D, Taoka M, Nance KD, Nir R, Bryson KM, Shachar R, Liman GLS, Burkhart BW, et al. 2020. Dynamic RNA acetylation revealed by quantitative cross-evolutionary mapping. Nature 583: 638-643. doi:10.1038/s41586020-2418-2

Sauerwald A, Sitaramaiah D, McCloskey JA, Söll D, Crain PF. 2005. $N^{6}$-acetyladenosine: a new modified nucleoside from Methanopyrus kandleri tRNA. FEBS Lett 579: 2807-2810. doi:10 .1016/j.febslet.2005.04.014

Selmer M, Dunham CM, Murphy FV, Weixlbaumer A, Petry S, Kelley AC, Weir JR, Ramakrishnan V. 2006. Structure of the 70S ribosome complexed with mRNA and tRNA. Science 313: 19351942. doi:10.1126/science. 1131127

Shigi N, Suzuki T, Terada T, Shirouzu M, Yokoyama S, Watanabe K. 2006. Temperature-dependent biosynthesis of 2-thioribothymidine of Thermus thermophilus tRNA. J Biol Chem 281: 21042113. doi:10.1074/jbc.M510771200

Sugahara J, Kikuta K, Fujishima K, Yachie N, Tomita M, Kanai A. 2008. Comprehensive analysis of archaeal tRNA genes reveals rapid increase of tRNA introns in the order thermoproteales. Mol Biol Evol 25: 2709-2716. doi:10.1093/molbev/msn216

Takakura M, Ishiguro K, Akichika S, Miyauchi K, Suzuki T. 2019. Biogenesis and functions of aminocarboxypropyluridine in tRNA. Nat Commun 10: 5542. doi:10.1038/s41467-019-13525-3

Tang TH, Polacek N, Zywicki M, Huber H, Brugger K, Garrett R, Bachellerie JP, Hüttenhofer A. 2005. Identification of novel noncoding RNAs as potential antisense regulators in the archaeon 
Sulfolobus solfataricus. Mol Microbiol 55: 469-481. doi:10.1111/j .1365-2958.2004.04428.x

Tomikawa C, Ohira T, Inoue Y, Kawamura T, Yamagishi A, Suzuki T, Hori H. 2013. Distinct tRNA modifications in the thermo-acidophilic archaeon, Thermoplasma acidophilum. FEBS Lett 587: 35753580. doi:10.1016/j.febslet.2013.09.021

Urbonavicius J, Armengaud J, Grosjean H. 2006. Identity elements required for enzymatic formation of N2,N2-dimethylguanosine from N2-monomethylated derivative and its possible role in avoiding alternative conformations in archaeal tRNA. J Mol Biol 357: 387399. doi:10.1016/j.jmb.2005.12.087

Urbonavicius J, Auxilien S, Walbott H, Trachana K, GolinelliPimpaneau B, Brochier-Armanet C, Grosjean H. 2008. Acquisition of a bacterial RumA-type tRNA(uracil-54, C5)-methyltransferase by Archaea through an ancient horizontal gene transfer. Mol Microbiol 67: 323-335. doi:10.1111/j.1365-2958.2007.06047.x

Vendeix FA, Murphy F, Cantara WA, Leszczynska G, Gustilo EM, Sproat B, Malkiewicz A, Agris PF. 2012. Human tRNA(Lys3)(UUU) is pre-structured by natural modifications for cognate and wobble codon binding through keto-enol tautomerism. J Mol Biol 416: 467-485. doi:10.1016/j.jmb.2011.12.048

Wagner TM, Nair V, Guymon R, Pomerantz SC, Crain PF, Davis DR, McCloskey JA. 2004. A novel method for sequence placement of modified nucleotides in mixtures of transfer RNA. Nucleic Acids Symp Ser 48: 263-264. doi:10.1093/nass/48.1.263

Watanabe M, Matsuo M, Tanaka S, Akimoto H, Asahi S, Nishimura S, Katze JR, Hashizume T, Crain PF, McCloskey JA, et al. 1997. Biosynthesis of archaeosine, a novel derivative of 7-deazaguano- sine specific to archaeal tRNA, proceeds via a pathway involving base replacement on the tRNA polynucleotide chain. J Biol Chem 272: 20146-20151. doi:10.1074/jbc.272.32.20146

Watson ZL, Ward FR, Méheust R, Ad O, Schepartz A, Banfield JF, Cate JHD. 2020. Structure of the bacterial ribosome at $2 \AA$ resolution. eLife 9: e60482. doi:10.7554/eLife.60482

Westhof E, Yusupov M, Yusupova G. 2019. The multiple flavors of GoU pairs in RNA. J Mol Recognit 32: e2782. doi:10.1002/jmr .2782

Wintermeyer W, Zachau HG. 1975. Tertiary structure interactions of 7methylguanosine in yeast tRNA ${ }^{\text {Phe }}$ as studied by borohydride reduction. FEBS Lett 58: 306-309. doi:10.1016/0014-5793(75) 80285-7

Yarus M. 1982. Translational efficiency of transfer RNA's: uses of an extended anticodon. Science 218: 646-652. doi:10.1126/science 6753149

Yu N, Jora M, Solivio B, Thakur P, Acevedo-Rocha CG, Randau L, de Crécy-LagardV, Addepalli B, Limbach PA. 2019. tRNA modification profiles and codon-decoding strategies in Methanocaldococcus jannaschii. J Bacteriol 201: e00690-18. doi:10.1128/JB.00690-18

Zago MA, Dennis PP, Omer AD. 2005. The expanding world of small RNAs in the hyperthermophilic archaeon Sulfolobus solfataricus. Mol Microbiol 55: 1812-1828. doi:10.1111/j.1365-2958.2005 .04505.x

Ziesche SM, Omer AD, Dennis PP. 2004. RNA-guided nucleotide modification of ribosomal and non-ribosomal RNAs in Archaea. Mol Microbiol 54: 980-993. doi:10.1111/j.1365-2958.2004 $.04319 . x$ 

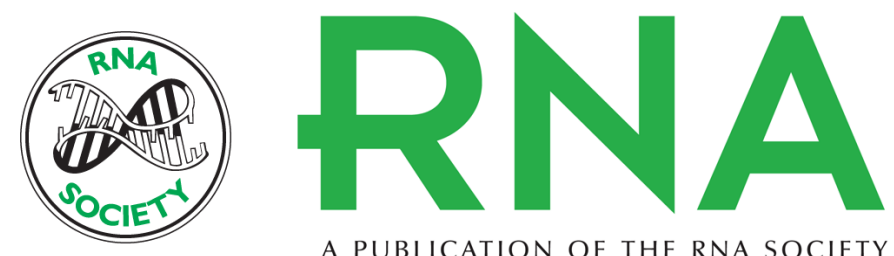

A PUBLICATION OF THE RNA SOCIETY

\section{Comparative patterns of modified nucleotides in individual tRNA species from a mesophilic and two thermophilic archaea}

Philippe Wolff, Claire Villette, Julie Zumsteg, et al.

RNA 2020 26: 1957-1975 originally published online September 29, 2020

Access the most recent version at doi:10.1261/rna.077537.120

\section{Supplemental http://rnajournal.cshlp.org/content/suppl/2020/09/29/rna.077537.120.DC1 \\ Material}

References This article cites 88 articles, 21 of which can be accessed free at: http://rnajournal.cshlp.org/content/26/12/1957.full.html\#ref-list-1

Open Access Freely available online through the RNA Open Access option.

Creative This article, published in RNA, is available under a Creative Commons License Commons (Attribution 4.0 International), as described at

License http://creativecommons.org/licenses/by/4.0/.

Email Alerting Receive free email alerts when new articles cite this article - sign up in the box at the Service top right corner of the article or click here.

\section{|||||||| Providing Precise Solutions for} your research.

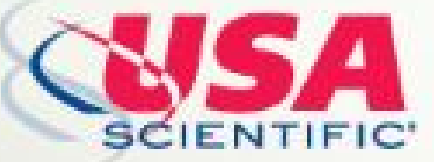

To subscribe to $R N A$ go to:

http://rnajournal.cshlp.org/subscriptions

(C) 2020 Wolff et al.; Published by Cold Spring Harbor Laboratory Press for the RNA Society 